\title{
Reversals in Global Market Integration and Funding Liquidity
}

Akbari, Amir, Francesca Carrieri, and Aytek Malkhozov

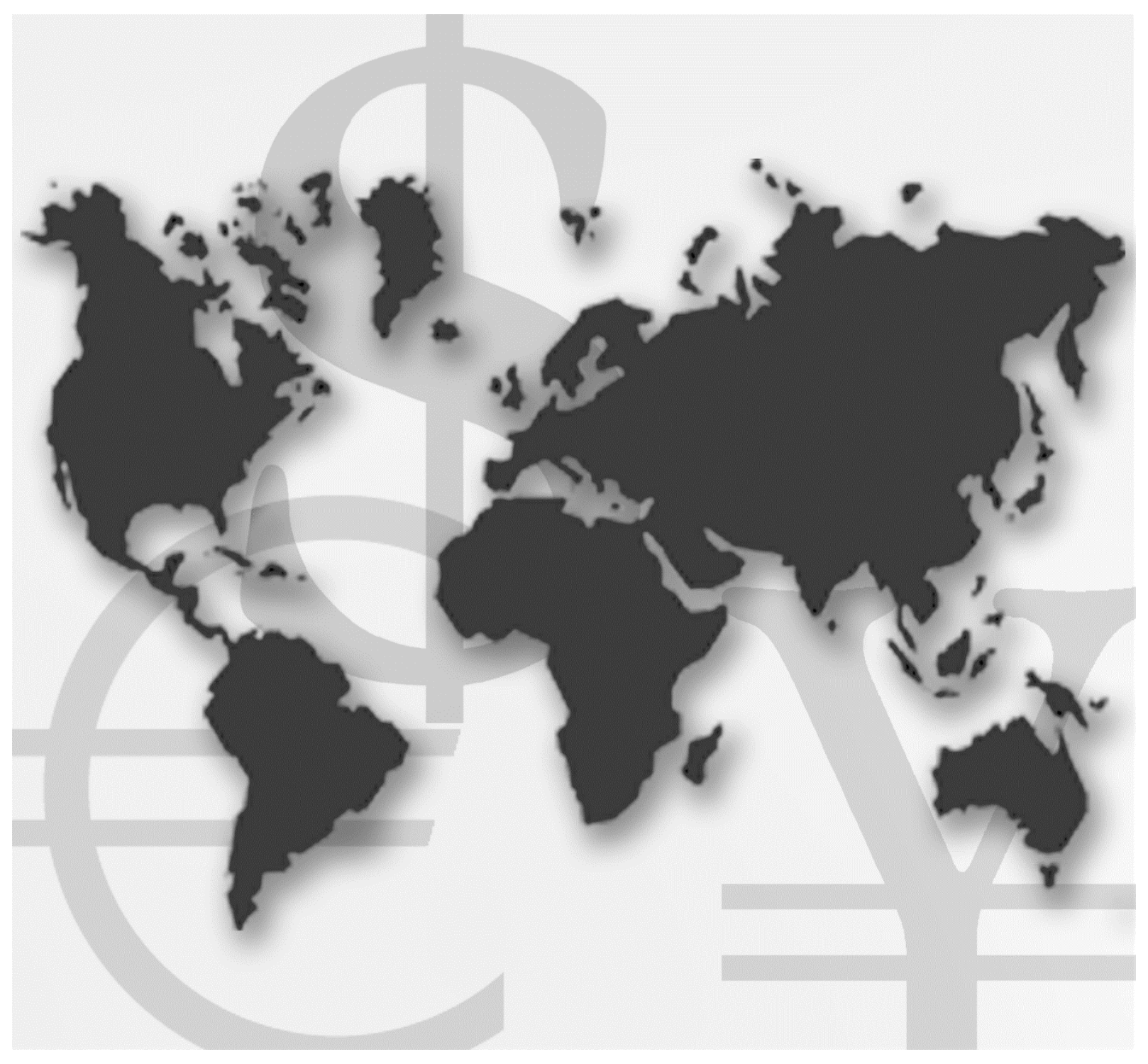

\section{International Finance Discussion Papers}

Board of Governors of the Federal Reserve System

Number 1202

March 2017 
Board of Governors of the Federal Reserve

System International Finance Discussion Papers

Number 1202

March 2017

\title{
Reversals in Global Market Integration and Funding Liquidity
}

\author{
Amir Akbari \\ Francesca Carrieri \\ Aytek Malkhozov
}

NOTE: International Finance Discussion Papers are preliminary materials circulated to stimulate discussion and critical comment. References to International Finance Discussion Papers (other than an acknowledgment that the writer has had access to unpublished material) should be cleared with the author or authors. Recent IFDPs are available on the Web at www.federalreserve.gov/pubs/ifdp/. This paper can be downloaded without charge from Social Science Research Network electronic library at www.ssrn.com. 


\title{
Reversals in Global Market Integration and Funding Liquidity
}

\author{
Amir Akbari \\ UOIT \\ Francesca Carrieri \\ McGill University \\ Aytek Malkhozov \\ Federal Reserve Board *
}

\begin{abstract}
This paper looks at the reversals in global financial integration through the funding liquidity lens. First, we construct a segmentation indicator based on differences in funding liquidity across countries as measured by the performance of betting-againstbeta strategies. Second, we find that funding liquidity shocks help explain recent reversals in integration in the absence of explicit foreign investment barriers. These findings are consistent with tighter limits to arbitrage and increased home bias during funding distress periods. Our empirical analysis is guided by a margin-CAPM model generalized to an international setting.
\end{abstract}

Keywords: International Finance, Market Segmentation, Integration Reversals, Funding Liquidity JEL classification: F36, G01, G12, G15.

${ }^{*}$ The views in this paper are solely the responsibility of the authors and should not be interpreted as reflecting the views of the Board of Governors of the Federal Reserve System or of any other person associated with the Federal Reserve System. We are grateful to Patrick Augustin, Ines Chaieb, Benjamin Croitoru, John Doukas, Vihang Errunza, Mariassunta Giannetti, Allaudeen Hameed, Alexandre Jeanneret, Hugues Langlois, Marc Lipson, Babak Loftaliei, Lilian Ng, Sergei Sarkissian, and David Schumacher for their helpful comments. 


\section{Introduction}

Financial markets became more integrated internationally over the past decades. Researchers attributed this long-run trend to the progressive reduction of barriers to foreign investment around the world, such as capital controls or taxes on repatriation. ${ }^{1}$ However, reversals in market integration, i.e. transitory increases in market segmentation, are at odds with the permanent removal of such impediments. Reversals occur, for instance, during financial crises when cross-border investment activity becomes severely disrupted, despite no notable increase in explicit investment barriers. ${ }^{2}$ Moreover, fundamental shocks tend to become more correlated during crisis periods, which further challenges the analysis of market integration dynamics. ${ }^{3}$

In this paper, we shed new light on the dynamics of global market integration by considering the role of leverage- and margin-constrained investors in international financial markets. Our contribution is twofold. First, we construct a new market segmentation indicator based on the dispersion in the returns of the country betting-against-beta (BAB) portfolios. Our approach is to infer the degree of market segmentation from the differences in country-level funding liquidity that drives the performance of BAB strategies. Second, we find that reversals in market integration are related to funding liquidity shocks, suggesting that the ease with which investors can fund their international positions is an important driver of market integration, in addition to the level of other investment barriers.

As a first step, we build an international asset pricing model where we assume that investors have to fund a fraction of their position in each asset with their own capital. Capital requirements are assumed to be not only investor-specific but also country-specific, which allows for heterogeneity in investors' access to countries. ${ }^{4}$ In equilibrium, each security commands a premium proportional to its exposure to market risk, as well as a compensation for the capital required to maintain the position in this security. Country BAB portfolios, that are long the low-beta assets and short the high-beta assets in their respective countries, are constructed to have zero exposure to global market risk and load on the country funding component. In perfectly integrated financial markets, country BAB returns depend on how binding the funding constraint is for the representative international

\footnotetext{
${ }^{1}$ See Bekaert and Harvey (1995), Carrieri, Errunza, and Hogan (2007), Bekaert, Harvey, Lundblad, and Siegel (2011, 2013), Carrieri, Chaieb, and Errunza (2013), and Eiling and Gerard (2014), among others.

${ }^{2}$ Lehkonen (2014) directly tests and documents lower market integration levels during the East Asia crisis, dot-com crash, and sub-prime crisis.

${ }^{3}$ See Carrieri et al. (2007) and Pukthuanthong and Roll (2009) who discuss empirical and theoretical issues with using market-wide correlations across countries as a measure of market integration.

${ }^{4}$ The model builds on Frazzini and Pedersen (2014). Chen and Lu (2014) and Malkhozov, Mueller, Vedolin, and Venter (2014) also consider a similar setting but for different applications.
} 
investor, and therefore should be highly correlated. When foreign investment barriers are present, funding shocks to a given investor have differential impact on this investor's home and foreign markets. As a result, $\mathrm{BAB}$ returns become more dispersed.

We construct the BAB portfolios across 62 countries (25 developed markets and 37 emerging markets) at monthly frequency from daily firm-level stock prices for the period from 1973 to 2014. The average returns of these country BAB portfolios are large and positive for most countries, confirming our premise that funding liquidity is an important consideration for global investors. BAB portfolios correlate more strongly among developed markets, compared to emerging markets. In crisis periods, BAB portfolios tend to comove less across countries, in stark contrast to country market-wide portfolios that have been shown in previous research to comove more. ${ }^{5}$

Building on these results, we construct a Funding-liquidity Segmentation Indicator (FSI) based on the measures of global funding illiquidity extracted from countries' BAB portfolio returns. Specifically, we use Bayesian methods to estimate the shadow price of the funding constraint for the marginal investor in each market. In the context of the model and under the null of no segmentation, all the shadow prices measure the global representative investor's funding liquidity and are the same across markets. However, they differ if capital markets are not perfectly integrated. We measure segmentation for a given country as the aggregate distance of its shadow price from those of the other markets.

This newly introduced segmentation indicator fits the previously documented evidence on market segmentation. First, the FSIs of developed markets are 30 percent smaller than those of emerging markets. In addition, the FSIs of all markets exhibit downward trends. Such trend is larger for the emerging markets, consistent with the impact of the progressive reductions of foreign investment barriers around the world.

More interestingly, FSI also indicates substantial reversals in market integration. These reversals coincide with periods of tight global funding constraints and cannot be accounted for by the existing explanations in the literature. Indeed, we find a positive and statistically significant association between FSI and commonly used measures of global funding illiquidity, even after controlling for the previously studied explanatory factors of market segmentation. The association with funding illiquidity holds when we use an alternative measure of market segmentation based on the difference in monthly price-to-earnings ratios of industry portfolios across countries proposed by Bekaert et al. $(2011,2013)$ (BHLS hereafter). Finally, for each country we also find a positive association between local funding illiquidity and both the FSI and BHLS measures of that country.

\footnotetext{
${ }^{5}$ See Huang, Lou, and Polk (2014) and Bali, Brown, Murray, and Tang (2014) for additional evidence on the performance of $\mathrm{BAB}$ portfolios through time.
} 
Our analysis is careful in distinguishing the funding liquidity and market liquidity channels. Research has demonstrated the role of liquidity risk in international investments and has shown that liquidity risk as a priced local factor may lead to valuation differentials (see for example Bekaert, Harvey, and Lundblad (2007) and Lee (2011)). However, the effect of funding liquidity due to constraints on intermediaries' capital is different from the effect of asset liquidity, although the two could potentially be linked (Brunnermeier and Pedersen (2009)). We control for local market liquidity and find an insignificant relationship between market liquidity and FSI, consistent with the results of Goyenko and Sarkissian (2014).

Our findings of higher level of market segmentation during funding shocks are supported by the recent research on cyclicality of international capital flow (for example see Rey (2015)). During high market volatility, when the VaR (capital) constraints of large financial institutions are more bindings, international credit inflows and portfolio debt inflows drop significantly across markets. On the contrary, during calm market periods, inflows grow across all markets leading to higher market integration. Gârleanu, Panageas, and $\mathrm{Yu}$ (2015) show that small variations in market access costs across different locations may cause abrupt deleveraging and portfolio-flow reversals in bad times. In this case, the resulting outflows from the leveraged strategies reduce aggregate market integration and push down the prices of risky securities.

While providing an explanation for reversals in market integration, this paper contributes to the literature on international asset pricing by linking it to the one on limits to arbitrage and home bias. The literature of intermediary asset pricing and limits to arbitrage shows that frictions, such as funding illiquidity, could result in deviations from the Law of One Price (LOP). ${ }^{6}$ Influential theoretical research in this literature includes Shleifer and Vishny (1997), Basak and Croitoru (2000), Gromb and Vayanos (2002), Brunnermeier and Pedersen (2009), Geanakoplos (2010), Gârleanu and Pedersen (2011), Ashcraft, Gârleanu, and Pedersen (2011), Duffie and Strulovici (2012), He and Krishnamurthy (2012, 2013), Fostel and Geanakoplos (2013), Adrian and Shin (2014). There is extensive empirical research on funding constraints and asset prices confirming the findings of these theoretical explanations (for a short list of recent research see Hameed, Kang, and Viswanathan (2010), Ang, Gorovyy, and van Inwegen (2011), Hu, Pan, and Wang (2013), Adrian, Muir, and Etula (2014), Pasquariello (2014), Frazzini and Pedersen (2014), and Fleckenstein, Longstaff, and Lustig (2014)). Temporary deviations from the LOP match the definition of

\footnotetext{
${ }^{6}$ As Pontiff (2006) shows, this effect is larger for more volatile assets, such as those in emerging markets, where idiosyncratic risk reduces demand for a mispriced asset and dampens arbitrage activity due to the hedging demand.
} 
reversals, where similar assets with identical cash flows are priced differently across international markets (Chen and Knez (1995)). Literature on the dynamics of home bias, such as Warnock and Warnock (2009), Hoggarth, Mahadeva, and Martin (2010), Jotikasthira, Lundblad, and Ramadorai (2012), and Giannetti and Laeven (2012, 2015) also suggests a link between funding illiquidity and reversals in market integration, documenting that the home bias of institutional investors increases following funding shocks. ${ }^{7}$ These investors are responsible for most cross-country investments; therefore, the frictions they face directly affect international asset prices and the global integration process. As they "fly home" more risk should be borne by local investors, which would increase market segmentation.

The dynamics of financial integration matter for international risk sharing and the cost of capital across countries and thus reversals can have important consequences. The funding illiquidity channel explored in this paper adds a new dimension to the existing research on those dynamics (see for instance, Carrieri et al. (2007), Pukthuanthong and Roll (2009), Bekaert et al. (2011), and Carrieri et al. (2013)). This strand of research, building on the theoretical international finance models, characterizes the role of explicit and implicit barriers in foreign investments. ${ }^{8}$ The current paper argues that short-term reversals in the level of market integration, contrary to the long-term trend and cross-sectional differences, are difficult to explain by the decreasing severity of the barriers that we have observed in the last few decades. On the other hand, these dynamics can be partially explained by short-term funding frictions, which are contemporaneous with most of the reversals.

The rest of the paper is organized as follows. Section 2 introduces the model and the Funding-liquidity Segmentation Indicator. The data and the estimation results are presented in Sections 3 and 4. Section 5 concludes.

\section{Model}

In this section, we describe the model setting and introduce the Funding-implied Segmentation Indicator (FSI).

\footnotetext{
${ }^{7}$ See Coeurdacier and Rey (2013) for a recent survey on the research on home bias.

${ }^{8}$ Early work in the theoretical international finance includes Black (1974), Stulz (1981), and Errunza and Losq (1985).
} 


\subsection{International Margin-CAPM}

Since institutional investors are the marginal investor in international markets, the frictions that they face directly affect international prices and consequently, market integration. Inability to borrow, as in Frazzini and Pedersen (2014), is one of these frictions that has attracted the growing attention of researchers, especially in the aftermath of the 2008 financial crisis. Extending their model, in this section we study the segmentation implication of an International Margin-CAPM that incorporates borrowing frictions for investors in international markets.

Frazzini and Pedersen (2014) show that financially constrained investors, who cannot buy on margin, overweight high-beta securities. ${ }^{9}$ This extra demand consequently reduces the premium of these securities because of their efficiency as liquidity providers. Therefore, a beta-neutral portfolio that longs the low-beta portfolio and shorts the high-beta portfolio has a positive premium. The $\mathrm{BAB}$ premium increases as more investors face tighter funding constraints. We extend their paper to an international setting and study the implication of a simple asset pricing framework that incorporates funding frictions for global equity market integration. Funding frictions are modeled through country-specific and investorspecific margins. ${ }^{10}$ This setting allows us not only to study the impact of borrowing frictions on global market integration but also to explore the role of institutional investors in this process.

We consider an overlapping-generations (OLG) economy with $I(i=1, \ldots, I)$ meanvariance optimizer agents in $K(k=1, \ldots, K)$ countries and $J(j=1, \ldots, J)$ risky securities. In each period $t$, agents are born with wealth $W_{i, t} \geq 0$, and they invest internationally subject to their margin constraints. In the next period, $t+1$, agents consume and exit the economy. The risky securities are in total supply of $\theta_{t}^{j}$, and each pay real dividends $D_{t}^{j}$ in the unique consumption good in period $t$. Their ex-dividend price is denoted by $P_{t}^{j}$. Investors maximize their utility by choosing a portfolio of risky assets and investing the rest of their wealth at the risk-free rate $r^{f}$. In matrix notation, each investor maximizes:

$$
\max _{\mathbf{x}_{i, t}} x_{i, t}^{\top}\left(E_{t}\left[P_{t+1}+D_{t+1}\right]-\left(1+r^{f}\right) P_{t}\right)-\frac{\gamma_{i}}{2} x_{i, t}^{\top} \Omega_{t} x_{i, t},
$$

\footnotetext{
9 The literature provides several other explanations for the flatness of the security market line (SML). A short list of recent explanations includes investors' disagreement (Hong and Sraer (2015)), sentiments (Antoniou, Doukas, and Subrahmanyam (2014)), delegated portfolio management (Brennan, Cheng, and Li (2012), Baker, Bradley, and Wurgler (2010)), forward-looking beta (Buss and Vilkov (2012)), lottery demand (Bali et al. (2014)), trading activity of arbitrageurs (Huang et al. (2014)), and missing state variables (Campbell, Giglio, Polk, and Turley (2012)).

${ }^{10}$ Chen and Lu (2014) and Malkhozov et al. (2014) also study asset and investor margins.
} 
where $x_{i, t}=\left[x_{i, t}^{1}, \ldots, x_{i, t}^{J}\right]$ is the vector of portfolio choice of investor $i$ and includes the number of shares she invests in each asset. $\gamma_{i}$ denotes the agent $i$ 's coefficient of risk aversion and $\Omega$ is the covariance matrix of asset prices. Investors are margin constrained. This implies that they must finance a fraction of their investment, i.e. the margin requirement for their portfolio choices, through their own capital and cannot fully borrow. ${ }^{11}$

$$
\sum_{j=1}^{J} m_{i, t}^{k}\left|x_{i, t}^{j}\right| P_{t}^{j} \leq W_{i, t}, \quad \forall j \in k .
$$

The constraint requires that the sum of the total dollar margins invested by agent $i$ be less than her wealth. $\psi_{i, t} \geq 0$ is the shadow price of the margin constraint of each investor and measures the "difficulty to borrow" of investor $i$ at time $t$.

The assumption of time-varying investor-specific and country-specific margins is supported by research and practice. Large institutional investors are less financially constrained and they can lever up their portfolio easier. Research has shown that more volatile assets require higher margins (see Fostel and Geanakoplos (2008), Jurek and Stafford (2010) and the references therein) because of the devaluation risk of the underlying asset. In practice, the Chicago Mercantile Exchange (CME) Group's approach is to adjust margin requirements based on historical, intraday, and implied volatilities (see Figure 1). ${ }^{12}$ In domestic market, Gorton and Metrick (2010) provide evidence on time variation and cross-sectional differences of Repo Haircuts backed by different securities.

\section{[Place Figure 1 about here]}

Ceteris paribus, it is more difficult to borrow against highly volatile stocks from emerging markets compared to large stable stocks from developed markets. Therefore, we assume country-specific margins, that is, all assets in a market require similar asset-specific margins. Since emerging markets have persistently higher volatilities than developed markets, it is expected to observe heterogeneity of margin requirements among international assets. ${ }^{13}$

Both long and short trades require margins and for simplicity in Equation (2), it is assumed that long and short positions require similar margin deposits. Margins can get values above one or less than one, depending on the investor's conditions. If the investor cannot borrow, as in Black (1972), $m_{i, t}^{k}=1$. Margin requirements less than one imply that

\footnotetext{
11 Ashcraft et al. (2011) study in more detail the relationship between investors' ability to borrow and margin constraints and they argue that investors' leverage is mainly constrained due to required margins.

${ }^{12}$ Reference: www.cmegroup.com/clearing/files/cme-clearing-margins-quick-facts-2011.pdf

${ }^{13}$ From personal discussions with portfolio managers of institutional investors, they confirm that in practice margins are also set based on the location of assets, due to differences in perceived foreign investment risk of securities, such as political or corruption risk.
} 
investors can borrow $\left(1-m_{i, t}^{k}\right)$ portion of the underlying price, using it as the collateral. Margin requirements greater than one imply that investors should hold portion of their wealth in cash, for example in order to meet daily redemptions or to pay claims.

Under the null of no segmentation, all assets, irrespective of their origin, are priced by a unique pricing kernel. Thus a subgroup of investors (e.g. the U.S. investors) do not face barriers to investment for a subgroup of assets (e.g. Indian stocks) in the form of higher margin requirements. In other words, all foreign and domestic investors are equally constrained with respect to assets in country $k$. As a result, we can decompose the margin requirement of investor $i$ for asset $j$ in country $k$ to separate country-specific and investor-specific margins. Formally, we have $m_{i}^{k}=m_{i} m^{k}, \forall j \in k$; which means margins are set irrespective of the location of the investor.

This setting fully nests traditional barriers to investments as discussed in the international finance literature. If an asset in a country $k$ is totally inaccessible to investor $i$, then the required margin for that asset from investor $i$ is infinite. ${ }^{14}$ However, this paper does not focus on this case but rather explores the post-liberalization period, a time when traditional barriers to foreign investment had been lifted for many countries around the world. In a similar setting, Malkhozov et al. (2014) study the asset pricing implications of barriers to investment in a Margin-CAPM framework and derive predictions regarding the effect of illiquidity on the cross-section of international stock returns in G7 countries. The case of mild segmentation in this framework is discussed in the appendix.

Under these assumptions and under the null of no segmentation, we derive the following International Margin-CAPM: ${ }^{15}$

$$
E_{t}\left[r_{t+1}^{j}\right]-r^{f}=\beta_{t}^{j} \lambda_{t}+\psi_{t}\left(m_{t}^{k}-\beta_{t}^{j} m_{t}^{G}\right) \quad \forall j \in k
$$

Here, the betas are with respect to the global market return, and the risk premium, $\lambda_{t}$, is for the global market risk. $\psi_{t}$ is the shadow price of the funding constraint of the global representative investor and $m_{t}^{G}$ is the aggregated margin required for the global market portfolio.

If margin constraints are not binding, i.e. when $\psi_{t}=0$, then the model reverts to the basic single-factor CAPM. ${ }^{16}$ However, assuming investors are financially constrained, assets that require higher margins relative to the average asset, command extra premiums. Specifically, assets from high margin countries command an additional premium, $\psi_{t} m_{t}^{k}$, since more capital is required to hold a position in those assets. Similarly, a higher

\footnotetext{
${ }^{14}$ See Black (1974) and Stulz (1981) for similar argument with infinite taxes.

${ }^{15}$ Detail mathematical derivations are in Appendix A

${ }^{16}$ We assume purchasing power parity holds; thus, there is no exchange risk premium.
} 
global margin increases required return on the global market portfolio, which decreases the expected excess return of assets by $-\psi_{t} \beta_{t}^{j} m_{t}^{G}$. Assuming similar country-specific margins internationally, i.e. where $m_{t}^{k}=1$, we have $m_{t}^{G}=1$ and thus our International Margin-CAPM reverts to the Frazzini and Pedersen's model (Equation (21)). Note that under the null of no segmentation, we have a representative investor, that is, no variable in Equation (3) has the index $i$, and only global factors are in the pricing kernel. Similarly, Gârleanu and Pedersen (2011), studying asset-specific margins in a domestic setting, show that high-margin assets have higher expected returns, especially during funding liquidity droughts.

Large values of $\psi_{t}$, the shadow price of the margin constraint for the global representative investor, imply tight funding conditions for the aggregate world economy. Therefore, $\psi_{t}$ is interpreted as the funding liquidity of the global representative investor (see Frazzini and Pedersen (2014)). We estimate this variable from zero beta portfolios (BAB) constructed from Equation (3). Under the null of no segmentation, the International MarginCAPM implies that the expected return of the country $k$ 's BAB is:

$$
E_{t}\left[r_{B A B, t+1}^{k}\right]-r^{f}=\frac{\beta_{H, t}^{k}-\beta_{L, t}^{k}}{\beta_{H, t}^{k} \beta_{L, t}^{k}} m_{t}^{k} \psi_{t} .
$$

This expected return is determined by three components: the beta spread for country $k$, the level of margins for country $k^{\prime} s$ assets, and the shadow price of the funding constraint for the global representative investor. If we control for the first two country- $k$-specific components, the extracted funding liquidities of the global representative investor from each market should be comoving perfectly across markets under the null. If markets were segmented, investors in different countries would have their own shadow price of the funding constraint, $\psi_{t}^{k}$. Thus, one can construct a measure of market segmentation based on the discrepancies of the estimated of $\psi_{t}^{k}$ of any country pair. In an integrated world, capital flows freely across markets and by the force of arbitrage, prices of similar assets are set close to each other. This ensures that local funding illiquidity diversifies internationally, as investors (the international intermediaries) would meddle in the two markets to provide liquidity and to arbitrage away any deviation from the LOP. In this case, only the global funding liquidity enters in the pricing kernel. On the other hand, in a segmented world, capital cannot move freely and local funding liquidities persist.Hence, the shadow prices of the funding constraint may diverge. Therefore, any discrepancies between the estimated $\psi_{t}^{k}$ across markets imply that investors face market-specific frictions that cannot be diversified out; hence it could be interpreted as a measure of market segmentation. 


\subsection{Funding-implied Segmentation Indicator (FSI)}

This section introduced the Funding-implied Segmentation Indicator (FSI). This measure is constructed from the discrepancies of the shadow price of the funding constraints, estimated from the BAB portfolios and Equation (4).

We follow Frazzini and Pedersen's methodology in estimating BAB portfolios. That is, at each period $t$ and in each country $k$, all assets are ranked based on their betas with respect to global market portfolio and are grouped in two categories (high- and low-beta). In each group, securities are weighted by the beta ranks in that group. The BAB portfolio for country $k$ is then formed by longing the low-beta portfolio, leveraged to beta one, and shorting the high-beta portfolio, de-leveraged to a beta of one. ${ }^{17}$ Equation (4) shows that, once such portfolios are constructed, one can extract the funding liquidity of the global representative investors from the $\mathrm{BAB}$ portfolio in market $k$, while controlling for both the beta spread and margins. Assuming country-specific margins are well approximated by market volatility, $m_{t}^{k}=a+b \sigma_{k, t-1}$, we can rewrite Equation (4) as below:

$$
E_{t}\left[r_{B A B, t+1}^{k}\right]-r^{f}=\psi_{t} Z_{t}^{k}
$$

where, $Z_{t}^{k}$ is the product of global beta spread of assets in country $k,\left(\beta_{H}^{k}-\beta_{L}^{k}\right) / \beta_{H}^{k} \beta_{L}^{k}$, and lagged local market realized volatility, $\sigma_{k, t-1}$. Since funding liquidity is a persistent variable, in this paper, we employ latent variable methods, more specifically Markov Chain Monte Carlo (MCMC) and Gibbs Sampling, to estimate $\psi_{t}$. In a similar setting, Jostova and Philipov (2005) and Ang and Chen (2007) implement this methodology to estimate conditional market betas for a single-factor CAPM. With simulation analysis, they show that their approach generates significantly more precise beta estimates than several competing models. ${ }^{18}$ Our specification is:

$$
\begin{aligned}
r_{B A B, t+1}^{k}-r^{f} & =\psi_{t} \hat{Z}_{t}^{k}+\sigma_{b} \varepsilon_{t} \\
\psi_{t} & =\phi_{0}+\phi_{1}\left(\psi_{t-1}-\phi_{0}\right)+\sigma_{\psi} \epsilon_{t} .
\end{aligned}
$$

We assume that $\psi_{t}$ follows a stationary $\mathrm{AR}(1)$ process with mean reversion and we estimate $\phi_{0}, \phi_{1}, \sigma_{\psi}, \sigma_{b}$ with MCMC and Gibbs Sampler with normal distributions for priors of

\footnotetext{
${ }^{17}$ Methodological details of the procedure are in Appendix C.

${ }^{18}$ As an alternative methodology we could estimate $\psi_{t}$ with rolling-windows (Lewellen and Nagel (2006)). However, with this methodology the estimates only speak for the average funding liquidity over the window period and it is difficult to mark their variations to business dates. Moreover, rolling-window estimations are sensitive to outliers. Nonetheless, this methodology produces similar dynamics for $\psi_{t}$ and our results are robust.
} 
the unknowns. To ensure stationarity, prior for $\phi_{1}$ is a truncated normal between $(-1,1)$. By Bayes law, posterior distributions are proportional to the priors times the likelihoods, which are defined by Equation (5). Thus, we randomly draw 10,000 samples from the posteriors and take the average to estimate the mean of the parameters. The first 1,000 draws are excluded as they are considered the training set. We acknowledge the "errorin-variable" issue from the estimation of the beta spread and market volatility (since $\hat{Z}_{t}^{k}$ is estimated in the previous step), however implementing the Gibbs Sampler reduces such concerns. Detail of the estimation is in Appendix D.

Under the null of no segmentation, the estimates of $\psi_{t}$ from each market should be the same. On the other hand, in a segmented world these estimates diverge from each other, and thus the distance between $\psi_{t}^{k}$ and $\psi_{t}^{c}$ can be interpreted as an indicator of how market $k$ is segmented from market $c$. To construct the Funding-implied Segmentation Indicator (FSI), we estimate value-weighted discrepancies among $\psi_{t}$ pairs, and construct

$$
F S I_{t}^{c}=\sum_{k=1}^{K} w_{t}^{k}\left|\psi_{t}^{k}-\psi_{t}^{c}\right|,
$$

where, $w_{t}^{k}$ is the weight of country $k$ in the world market portfolio.

\subsection{A Segmentation Measure in the Literature}

To confirm the empirical relationship between funding illiquidity and reversals in international market integration independently from the FSI, we cross-validate our results with one of the existing measure of market segmentation in the literature.

The literature of international asset pricing has established that market-wide correlations are an inaccurate measure of market integration. In fact, market-wide correlations can only approximate market integration under strong assumptions for the underlying asset pricing kernel. ${ }^{19}$ To address these shortcomings, the literature has explored a number of alternative measures of market integration and segmentation, some of these ad-hoc, others based on international asset pricing theory. For our purposes, we use the measure of market segmentation that is introduced and studied in Bekaert et al. (2011, 2013); Bekaert, Harvey, Lundblad, and Siegel (2014), the $S E G$ index. This is a "model-free" measure, based on price-earning ratio differentials of industry portfolios across markets. BHLS argue that under the null of no segmentation industry portfolios have similar growth opportunities and similar systematic risk across markets, thus their PE ratios should be

\footnotetext{
${ }^{19}$ If the underlying asset pricing model has extra factors besides the market portfolio risk or if the prices of risk are time-varying, then market-wide correlations cannot represent market integration.
} 
similar. The degree of market segmentation for country $k$ at $t$ is computed as:

$$
S E G_{k, t}=\sum_{j=1}^{N} I W_{k, j, t}\left|E Y_{k, j, t}-E Y_{w, j, t}\right| .
$$

where we define the weight of industry $j$ in country $k$ at time $t$ by $I W_{k, j, t}$ and denote industry $j$ 's earnings yield in country $k$ as $E Y_{k, j, t}$. The authors construct industry portfolios by aggregating firm-level data, according to the DataStream 38 industry classification, and then calculate local earnings yield and portfolio weights to obtain the segmentation measure for each industry and country.

We choose this measure of market segmentation for our cross-validation because of data availability. Indeed the literature has provided alternative measures of market segmentation, which, although supported by theoretical models, are not fully suitable for our purpose. For example, Carrieri et al. (2007) introduce an index of market integration following the Errunza and Losq (1985) model of mild segmentation. This measure is based on the ratio of risk conditional on the diversification portfolios, the portfolios of assets that best span the foreign assets locally, to the total risk, but its application is limited by the data required to build the diversification portfolios. Pukthuanthong and Roll (2009) introduce an alternative measure of market integration that overcomes this data availability concern. Their measure is based on the R-square of a multi-factor asset pricing model estimated with each year observations and as a result, it is not suited for studies of higher frequencies.

All these measures document common patterns in the degree of market integration across countries. For example, it has been widely shown that some countries from developed markets are more integrated, compared to emerging markets. Moreover, this strand of research confirms that market integration is a time-varying process with an upward trend and acknowledges the presence of reversals. The long-term trend and crosssectional differences in market integration are largely explained by the severity of existing foreign investment barriers. For instance, Bekaert et al. (2011) investigate a wide range of macroeconomic and financial variables and with a general to specific search algorithm find support for seven of those variables. ${ }^{20}$ We control for those significant variables in the em-

\footnotetext{
${ }^{20}$ They study openness (equity market, capital account, and trade openness, trade to GDP), political risk and institutions (quality of institutions, corruption, law and order, bureaucratic quality, investment profile, legal origin), financial development (liquidity, market turnover, market synchronicity, past market return, private credit to GDP, market capitalization to GDP), risk appetite and business cycles (G7 real rate, U.S. money supply growth, risk aversion, credit spread, VIX, world GDP growth, world equity market volatility), information variables (phone lines, Internet users, international voice traffic), growth determinants (GDP, secondary school enrollment, life expectancy, population growth), plus a number of controls (number of public firms, absolute difference in financial leverage, earnings growth volatility, real interest rate). For
} 
pirical analysis while we argue that the mechanism by which the funding channel affects market segmentation is distinct from the previously studied barriers to investment. These barriers mainly include regulatory restrictions and measure host markets' capability to absorb international investments, whereas funding illiquidity measures investors' incentives and ease in committing capital across international markets.

\section{Data}

We collect the dollar denominated daily total return index, the market capitalization, and the Price-Earning ratio for all individual stocks that are available in DataStream and WorldScope databases. For country market data and global market portfolio, we use the DataStream market indexes that are available for 62 countries. According to the classification by Standard and Poor's (S\&P), 25 of these countries are developed (Australia, Austria, Belgium, Canada, Denmark, Finland, France, Germany, Hong Kong, Ireland, Israel, Italy, Japan, Luxembourg, Netherlands, New Zealand, Norway, Singapore, South Korea, Spain, Sweden, Switzerland, the U.K., and the U.S.), and 37 countries are emerging (Argentina, Bahrain, Brazil, Bulgaria, Chile, China, Colombia, Croatia, Cyprus, Czech Republic, Egypt, Greece, Hungary, India, Indonesia, Jordan, Kuwait, Malaysia, Malta, Mexico, Morocco, Nigeria, Oman, Pakistan, Peru, Philippines, Poland, Qatar, Romania, Russian Federation, Slovenia, South Africa, Sri Lanka, Taiwan, Thailand, Turkey, Venezuela). DataStream provides daily asset return data for 226,239 assets for the period from January 1973 to October 2014. We follow Karolyi, Lee, and van Dijk (2012) in cleaning the data. In DataStream we choose Equity as Data type and exclude depositary receipts (DRs), real estate investment trusts (REITs), preferred stocks, investment funds, and other stocks with special features. ${ }^{21}$ Moreover, we ensure each asset in the sample has at least 750 trading days of non-missing return data in a window of five years, required to estimate the asset beta (for details on beta estimation see Appendix C). To limit the effect of survivorship bias, the dead stocks are also included in the sample. The final sample (clean) includes 58,405 stocks. For the risk-free rate, we use one-month T-bill rates from Kenneth French's website.

As a measure for funding liquidity, we consider five proxies widely used in recent re-

more details on these variables see Appendix 2 of Bekaert et al. (2011).

21 The exclusion of these stocks is done manually by examining the names of the individual stocks, as neither DataStream nor WorldScope provide codes for discerning non-common shares from common shares. We drop stocks with names including "REIT," "REAL EST," "GDR," "PF," "PREF," or "PRF" as these terms may represent REITs, Global DRs, or preferred stocks. We drop stocks with names including "ADS," "RESPT," "UNIT," "TST," "TRUST," "INCOME FD," "INCOME FUND," "UTS," "RST," "CAP.SHS," "INV," "HDG," "SBVTG," "VTG.SAS," "GW.FD," "RTN.INC," "VCT," "ORTF," "HI.YIELD," "PARTNER," "HIGH INCOME," "INC.\&GROWTH," and "INC.\&GW" due to various special features. 
search, since there is no single agreed upon measure in the literature. Specifically, we consider proxies of funding liquidity in the U.S. market: the TED spread (calculated as the spread between the three-month LIBOR based on the U.S. dollars and the three-month Treasury Bill from Federal Reserve Bank of St. Louis), the VIX index (implied volatility of the S\&P 500 market index from CBOE website), the log of the broker-dealer total assets (from Table L.128 of the Federal Reserve Flow of Funds), the broker-dealer leverage (calculated using total financial assets divided by the total financial liabilities of security broker-dealers as captured in Table L.128 of the Federal Reserve Flow of Funds), and the fixed income-implied funding liquidity (from Jean-Sébastien Fontaine's website). The literature frequently uses the TED spread to proxy borrowing cost as it captures the difference between collateral and uncollateral borrowing rates (Gârleanu and Pedersen (2011)). The VIX index is not theoretically linked to the funding liquidity; however, it is considered informative of the state of the credit market because of the link between aggregate uncertainty (proxied by the VIX index) and the funding conditions (Ang et al. (2011)). The intermediary asset pricing literature provides convincing arguments suggesting that the balance sheet and asset holding of large institutional investors are informative of the funding conditions of the whole market. More specifically, Adrian and Shin (2010) suggest that the broker-dealers' asset growth corresponds to changes in their debt capacity. Since financial intermediaries manage their value-at-risk, asset growth is immediately followed by active balance sheet adjustments that result in a higher overall leverage. Adrian et al. (2014) follow this idea by proposing the broker-dealers' leverage factor, which indicates the financial difficulty the intermediaries face in funding their daily trades. Fontaine and Garcia (2012) similar to Hu et al. (2013) measure funding illiquidity from the cross-section of Treasury securities. Increases in the TED spread, the VIX index and the fixed income-implied measure imply worsening in the funding conditions. Conversely, decreases in the broker-dealer total assets and leverage imply decreases in funding liquidity of the economy. Although these proxies of funding liquidity generally comove with each other, they also have shown differences, as arguably some of them measure funding liquidity of the supply side and some others measure that of the demand side (see Boguth and Simutin (2015)). These measures are available with different frequencies and time periods. The TED spread and VIX index are available at a daily frequency, respectively from 1986 and from 1990. The broker-dealer balance sheet data is available at a quarterly frequency from 1968, while the fixed income-implied funding liquidity is available from 1986 with a monthly frequency. To match the datasets we take the last observations of the month (or quarter) to transform daily data to monthly (or quarterly) data.

Data for control variables are from DataStream, S\&P IFCI/IFCG, IMF e-Library, Oxford 
Economics, the World Bank WDI database, and the OECD National Accounts data files. For more details on these variables see Appendix 2 of Bekaert et al. (2011). Annual data are linearly interpolated to access higher frequency data when missing. As these macroeconomic variables are very persistent, the interpolation method should not have a large impact on the results.

\section{Empirical Results}

In this section, we study the effect of funding liquidity on market segmentation. First, we analyze the $B A B$ portfolios across markets, and we then introduce a Funding-liquidity Segmentation Indicator (FSI) based on these BAB portfolios. We separately study the FSI with respect to global and to local funding liquidity shocks, both in cross-sectional and time-series analyses, to provide supportive evidence of reversals that can be linked to borrowing frictions of intermediaries. The results of our analysis are then compared with the results using the BHLS measure of market segmentation.

\subsection{BAB Analysis}

We construct the betting against beta portfolio (BAB) that longs the low-global beta assets and shorts the high-global beta assets from each market's security-level returns, with a methodology similar to Frazzini and Pedersen (2014). Table 1 presents the descriptive statistics of these portfolios together with some other relevant statistics for the countries in the dataset. In the sample, developed markets have on average more firms in their crosssection, and lower monthly realized market volatilities, compared to emerging markets. The world market beta spreads, the difference between the reciprocal of the aggregate beta of high global beta portfolios and low global beta portfolios, are around 0.60 across developed markets. For emerging markets the beta spreads are instead in a much wider range, from 0.24 to 1.44 . This is possibly due to smaller exposure to the global market risk, lower cross-section of assets, and similar characteristics of the assets covered by the data vendor in emerging markets. For instance, the table shows that for some emerging markets DataStream provides return data only on a small cross-section of large companies. These companies have similar betas and therefore the beta spread is very small for these countries. On the other hand, for markets that have smaller exposure to the global market risk, both high-beta and low-beta are small and their beta spread is larger. The table also

presents the monthly average of $\mathrm{BAB}$ portfolio returns as well as their correlations with the $\mathrm{BAB}$ portfolio returns extracted from the U.S. market. Consistent with the findings of 
Frazzini and Pedersen (2014), in almost all countries the premium for the betting against beta is positive.

The International Margin-CAPM of Equation (4) shows that the BAB portfolios are betaneutral and load on the funding liquidity. The model implies that for markets with similar beta spread and similar country-specific margins, the BAB portfolios should highly comove, as they share the same shadow price of the funding constraint $\left(\psi_{t}^{k}\right)$ under the null of integration. Since previous research has documented a higher level of market integration among developed markets, we expect to observe higher BAB comovements in this subset of countries with similar market volatility (used here as a proxy of country-specific margins,) and similar beta spreads. This cross-sectional prediction is indeed supported by the data. We find higher (unconditional) correlations among BAB portfolio returns of the U.S. market with those of developed markets, as presented in Table 1. On the other hand, the table shows that the BAB portfolios of emerging markets have much lower (unconditional) correlations with the BAB portfolio of the U.S., implying that the funding shocks in these markets do not fully diversify out.

\section{[Place Table 1 about here]}

In addition to the cross-sectional implications, the International Margin-CAPM also suggests that the dynamics of the correlations of the BAB portfolios can characterize how funding shocks comove across international markets. For instance, if during global financial distress, investors "fly home" and international capital mobility drops in the aftermath, then funding liquidity shocks do not diversify across markets. Previous research in international finance has documented how correlations of market-wide country indices increase during financial distress (see for example Longin and Solnik (2001)). Therefore using those correlations to infer market integration goes against our intuition that international markets become less integrated at these times. Instead, as Equation (4) implies, we expect to observe lower BAB correlations across markets during these periods.

We estimate the time-varying correlations of the BAB portfolios of each market with that of the U.S. market with the Dynamic Conditional Correlations (DCC) specification as proposed by Engle (2002). ${ }^{22}$ We focus on developed markets and use the measures of funding liquidity in the U.S. market as the global funding liquidity proxies, assuming the funding liquidity shocks in the U.S. propagate to other markets. Indeed research has documented that international institutional investors, as the main cross-market investors, mostly rely on the U.S. market for their borrowing activities. Results of the regressions

\footnotetext{
22 The moving window correlations, while producing similar patterns with DCC, are difficult to mark to business dates.
} 
of the liquidity proxies on the estimated correlations are in Table 2. All proxies indicate that the correlations of the BAB portfolios decrease as funding constraints tighten. The TED spread, total assets of the broker-dealer, and fixed income-implied funding liquidity are estimated to be significantly negative. The VIX index and leverage of the brokerdealer are correctly estimated with a negative sign but at a lower statistical level. We also control for the correlation of the equity markets, to capture the global comovements between markets and to account for the effect of possible noise in estimating the betas and the market neutral $\mathrm{BAB}$ portfolios. The evidence from table 2 supports the implication of Equation (4), and shows that the funding liquidity risk is not fully diversified during distress periods. It is then likely that the existence of local asset pricing factors (shocks) translates to market segmentation and reversals in these periods.

\section{[Place Table 2 about here]}

\subsection{Funding-liquidity Segmentation Indicator (FSI)}

In light of the results in Section 4.1 and motivated by the International Margin-CAPM, in this section we introduce and study the Funding-liquidity Segmentation Indicator (FSI). As described in Section 2, FSI is constructed from the shadow prices of the margin constraint in the International Margin-CAPM that are estimated from assets of each market. Under the null of no segmentation, all these shadow prices, $\psi_{t}^{k}$, measure the global representative investor's funding liquidity, thus they are the same across markets. However, with segmentation, they diverge across countries as a consequence of global funding capital constraints. Therefore, for markets that are more integrated, we expect to observe higher comovements between the $\psi_{t}^{k}$ s. Figure 2 plots the unconditional correlations of these shadow prices with that of the U.S. market as a benchmark. In the plot, we observe that the $\psi_{t}^{k}$ s of developed markets (in blue) comove more strongly with that of the U.S. market, compared with the emerging markets (in red). This is consistent with previous research that documents developed markets to be more integrated with the U.S. market.

\section{[Place Figure 2 about here]}

Besides the cross-sectional implications, the International Margin-CAPM dictates equal $\psi_{t}^{k}$ across markets at each period $t$. The discrepancies between the extracted shadow prices of any pair of markets, $c$ and $k$, can thus be interpreted as the severity of the constraints to unimpeded flows on funding capital across the two markets at time $t$. The larger the distance between these prices, the higher the degree of market segmentation of market $c$ 
from $k$ and vice versa. Analogously, $F S I^{c}$, as the value-weighted average of the discrepancies between market $c$ and all other markets, can be an indicator of market segmentation for country $c$. Table 3 provides the summary statistics on this indicator. The table shows that the mean and maximum of the FSIs are larger for emerging markets. In fact, all top 15 maxima belong to FSIs of emerging markets. Conversely, 14 out of 15 minima are observed for FSIs of developed markets. The average of FSIs among developed markets is 0.61 , which is $34 \%$ smaller than the average among emerging markets. The smallest mean value of FSI is for the U.S. at 0.37, and the largest mean value of FSI is for Sri Lanka at 2.34. In addition, the standard deviations of the FSIs are smaller in developed markets compared to emerging markets. This finding is possibly related to the larger reduction in barriers to foreign investments experienced by emerging markets in recent years. These observations are consistent with information obtained from the BHLS measure of market segmentation, although FSI generally has a larger standard deviation and a smaller autocorrelation compared to that measure. This is not surprising, as the latter is averaged over the earning ratio of highly diversified industry portfolios, and the former is constructed from firm-level return data.

\section{[Place Table 3 about here]}

The newly introduced segmentation indicator fits the previously documented evidence on market segmentation. Table 4 presents test results on the statistical significance of FSIs across developed and emerging markets. This table reports the results of unbalanced pooled panel regressions (across all sample, only developed markets, and only emerging markets) as well as univariate estimations of the average FSIs (across developed and emerging markets). In the panel regressions, to account for heteroskedasticity, serial autocorrelations and cross-correlations in error terms, p-values are calculated based on the double clustered standard errors, through time and country, as instructed by Petersen (2009). In the univariate regressions, p-values are instead calculated with Newey and West (1987) heteroskedasticity and autocorrelation robust standard errors. In line with the observations from Table 3, the analysis in Table 4 confirms that the FSI of developed markets are smaller than those of the emerging markets. In all cases, the intercept of the developed markets, as the average value of the FSI, is estimated to be smaller. The one-sided t-test for the averages confirms that the FSIs in emerging markets are statistically larger than those of the developed markets. In addition, the table shows that for all markets there is a downward trend in FSIs, and that such trend is larger for the emerging markets, similar to what we find with the BHLS measure of market segmentation.

[Place Table 4 about here] 
Figure 3 plots the average measure of FSIs of the developed markets (in blue) and emerging markets (in red), visualizing the results from Table 4. Comparing across the two subsets, the figure indicates that emerging markets are less integrated with the world, compared to developed markets. Overtime, we see that both measures have a downward slope that is therefore consistent with the reduction of barriers to international investment. More interestingly, the plot shows that reversals in FSI coincide with large global financial crises and tightening of global funding conditions, as identified by increases in the TED spread (marked in black). We study this pattern in more details in Section 4.3.

\section{[Place Figure 3 about here]}

\subsection{Segmentation and Global Funding Illiquidity}

If we observe that during some periods access to capital is scarce and investors "fly home", as Giannetti and Laeven (2012) frame it, we can infer that at times investors across markets are unable to internationally share funding liquidity risk. Therefore, in these times, we expect larger international market segmentation. Conversely, when investors are not financially constrained and funding capital is freely accessible across international markets, risk sharing improves and market segmentation decreases. To test this hypothesis, in this section we study the relationship between global funding illiquidity and market segmentation. We start with the FSI as a measure of market segmentation and confirm out results with the BHLS measure.

Similar to the BAB analysis in Section 4.1, we focus on developed markets and test the comovements of the measure of market segmentation with proxies of global funding illiquidity measured by funding illiquidity in the U.S. Results of the FSI analysis are tabulated in Table 5. The regressions of Panel A include country intercepts and a time trend to capture the effect of time-invariant and time-varying barriers to investment but their estimates are not tabulated to save space. The untabulated results show that country intercepts are jointly significant and positive, implying that there exists heterogeneity in the level of market segmentation across these markets. We also observe that the coefficient of the time trend is estimated to be significant and negative, which is consistent with the progressive reduction of barriers in the recent period.

All the results in Table 5 show throughout that the newly introduced segmentation indicator is higher with tight global constraints and lower in relaxed periods. As the proxies of funding illiquidity are in different range and scale, the magnitudes of the coefficients are not comparable, but the sign of the estimated coefficients provides supportive evidence of 
a positive association of segmentation with funding illiquidity. As tabulated in Panel A, the coefficients for the TED spread, the VIX index, the broker-dealer leverage and the fixedincome funding liquidity are estimated to be positive and statistically significant. The estimate for the total assets of the broker-dealer is also estimated with the correct sign but at a lower significance level. These results are consistent with the implications from the research on international capital flows. For instance, Warnock and Warnock (2009) show that foreign inflows into U.S. Government Bonds dropped following the 1987 Black Monday, 1998 LTCM default and East Asia crashes, and the tech-bubble burst in 2001. ${ }^{23}$ As a result of this limited capital mobility in international markets, the shadow prices of global funding liquidity extracted from each country $\left(\psi_{t}^{k} \mathrm{~s}\right)$ diverge during funding crises and FSI, as an indicator of market segmentation, increases across markets (see Equation 3).

Previous research on the dynamics of market integration has provided support for the explanatory power of a number of variables as proxies of explicit or implicit barriers to investment. In Panel B we directly control for the previously studied barriers, such as equity and capital account openness, investment profile, market capitalization to GDP, U.S. corporate bond spread, and past market returns. Results confirm the positive association between FSI and funding liquidity. The coefficients for the TED spread, the VIX index, the broker-dealer leverage and total assets are positive and significant while the estimate for the fixed-income funding liquidity is also of the correct sign but with a lower significance level. Lee (2011) finds empirical evidence that local liquidity risks are priced in international financial markets. However, the effect of funding liquidity on capital mobility is different from the effect of asset liquidity, although the two are linked via liquidity spirals (Brunnermeier and Pedersen (2009)). We argue that the mechanism by which the funding channel affects market segmentation as explained in this paper is distinct from the previously studied barriers to investment. We control for local market liquidity and we show that reversals are not fully explained by local market liquidity. A comparison of Panel A and $\mathrm{B}$ reveals that substituting the country fixed effects and the trend with a set of control variables, as proxies of the barriers, does not substantially change the sign and magnitude of the coefficient estimates.

To strengthen the evidence on the conditional association between higher segmentation and periods of funding illiquidity we run quantile regressions. Panel C and D tabulate the results of the first and forth quantile regressions. In Panel C, the explanatory variable is a dummy variable that takes a value of one if the proxies for funding liquidity are above their 75 percentile and zeros otherwise. Thus, values of one for the dummy variable represents

\footnotetext{
${ }^{23}$ Giannetti and Laeven (2012) provide convincing evidence that the "flight home" effect is different from "flight to quality", where investors rebalance their portfolios toward less risky assets.
} 
here the tight funding conditions. Similarly, the explanatory variable in Panel D is a dummy variable that takes a value of one if the proxies for funding liquidity are less than their 25 percentile, and thus it identifies the relaxed funding conditions. The table shows that in Panel C, where we study the FSI conditional on the dummy of tight funding conditions, the coefficients are estimated to be always positive and in some instances highly statistically significant. Conversely, this association flips in relaxed funding periods and the statistical support mainly disappears. This evidence further confirms that the positive association between funding liquidity and the FSIs appears to be driven by the top quartile, i.e. periods with tighter-than-normal funding liquidity.

\section{[Place Table 5 about here]}

The theoretical models in the literature of limits to arbitrage (e.g. Basak and Croitoru (2000), Gârleanu and Pedersen (2011)) imply that market segmentation increases during funding distress periods. This strand of literature shows that deviations from LOP can occur during periods when investors' holding restrictions on redundant assets bind more, preventing them from undertaking arbitrage activities. ${ }^{24}$ As a result, investors cannot trade optimally to equalize the demand and the price of similar assets. Related to this research, Gromb and Vayanos (2002) show that when financial intermediaries who act as the liquidity providers in isolated markets are financially constrained, deviations from LOP occur. Such deviations match the definition of market segmentation, where assets of similar risk are priced differently across markets. That is, during funding illiquidity peaks, asset prices are governed by local demand and supply, as opposed to aggregate demand and supply for global markets. The financial intermediaries fail to execute the arbitrage strategy and cannot close the gap across markets between similar assets.

The higher market segmentation observed in response to a global funding shock aligns with reversals in capital flows. It has been documented that market portfolio comovements increase during market downturns (Longin and Solnik (2001)). Capital constraints of financial intermediaries are more likely to be hit during these periods, because most of these investors are net long in the local market (Brunnermeier and Pedersen (2009)). Therefore, during these periods one expects to observe contemporaneous funding shocks across countries, which are local in nature because of the limited capital mobility. Theoretically, investors trade less when funding constraints and margins bind more (see, for example, Chabakauri (2013) and Rytchkov (2014)). Moreover, investors are forced to tilt their holdings toward domestic assets in funding crisis periods (see, for instance, Jotikasthira

\footnotetext{
${ }^{24}$ Regulatory restrictions may allow only limited positions in certain assets or prohibit investors from taking short positions.
} 
et al. (2012)) and are incapable of trading freely across the world to internationally equalize asset demands. Recent research on slow-moving capital (Duffie (2010), Duffie and Strulovici (2012)) also supports commonality among deviations of LOP (and market segmentation) across markets. This strand of literature shows that during large shocks to the capital available to arbitrageurs, mispricing between securities in multiple markets simultaneously widens (Fleckenstein et al. (2014)).

To validate the interpretation of our findings, we broadly replicate the analysis of Table 5 with the BHLS measure of market segmentation. While the analysis in Bekaert et al. (2011) is with annual frequency, we work with monthly and quarterly frequencies to capture the effect of short-term funding illiquidity. We formally test for the relationship and present in Table 6 the results for the BHLS measure of developed markets. Panel A shows the results of a pooled panel regression with country fixed effects and a time trend to incorporate the effect of time-invariant and time-varying (implicit or explicit) barriers to investment across markets. In Panel A, the estimated coefficients of proxies of global funding liquidity in all regressions are positive and significant, except for the broker-dealer leverage. As stated above, these proxies of funding liquidity are in a different range and scale, therefore, the magnitude of the coefficients are not closely comparable. However, the sign of the estimated coefficients provides supportive evidence for a positive association of funding liquidity with segmentation.

\section{[Place Table 6 about here]}

We are concerned that the results in the above pooled panel regression could be driven by the link between the U.S. market segmentation and the U.S. proxies of funding liquidity, or that they are sample specific. We then run a few checks. At first, we exclude the U.S. market segmentation from the test assets. This exclusion has minuscule effect on the coefficient estimates, their t-stats, and the coefficient of determination (adj. $R^{2}$ ). Furthermore, excluding from the estimation observations of the years 2007-2009, we confirm that the positive association between the BHLS measure of market segmentation and funding illiquidity is not solely driven by the considerable worsening of the funding conditions during the subprime mortgage crisis in 2008. Nonetheless markets do become significantly segmented during this crisis, in parallel with the substantial deterioration of funding conditions across the globe. Finally, we exclude from the test the early periods as it has been argued that explicit barriers to investment were in place and effective, at least partly, till the early Nineties. This does not alter the conclusions of Panel A as we find that market segmentation loads positively and significantly on all proxies of funding illiquidity. ${ }^{25}$

\footnotetext{
${ }^{25}$ Results of the subsample tests are not tabulated to save space and are available upon request.
} 
In Panel B of Table 6, we control for previously studied barriers to investment, such as investment profile, trade to GDP, market returns and liquidity. We confirm that the positive association between market segmentation observed in Panel A is robust to the inclusion of these factors. All the estimated coefficients for the illiquidity proxies retain the sign and significance observed in the previous panel. ${ }^{26}$ More interestingly, including in this analysis factors related to funding liquidity, considerably increases the explanatory power of the regression in the reversal periods. We find that for the periods when the BHLS measure is high, the coefficient of determination ( $\left.a d j . R^{2}\right)$ of the regression almost doubles, increasing from 0.13 to 0.24 .

With the quantile regressions reported in Table 7, we find that the periods of shortterm increases in the BHLS measure (in other words, the reversal periods) coincide with periods of tighter funding constraints. ${ }^{27}$ In Panel A, we find that when explanatory factors are in their 75 percentile, the factors that are linked to funding illiquidity are significantly related to increases in the BHLS measure of market segmentation. On the other hand, when explanatory factors are in their 25 percentile, as in the analysis of Panel B, the funding liquidity measures mostly loose statistical significance. We do not observe the same pattern with respect to the other explanatory factors already studied in BHLS. While the sign for investment profile, trade to GDP, market returns flips, their significance is not broadly affected. Market liquidity is on the other hand still not significant.

\section{[Place Table 7 about here]}

Besides the statistical link of the funding proxies with the increases in the BHLS measure, we argue that the funding channel can also rationalize reversals better than the previously studied factors already linked to segmentation measures. In fact, there are no a priori expectations for decreases in investment profile or in capital account openness to occur in global financial crisis periods. ${ }^{28}$ Some implicit barriers such as information barriers, as measured by news coverage, are actually likely to decrease during financial crises, and thus they cannot provide a valid explanation for reversals. Neither can an increase in risk aversion, because it symmetrically affects the demand of local and foreign assets. Moreover, the empirical evidence for the importance of U.S. risk aversion for global markets is weak, as shown in Bekaert et al. (2011). On the other hand, one can argue that the

\footnotetext{
${ }^{26}$ Due to data availability, similar to Bekaert et al. (2011), Panel B does not cover observations after 2005. Excluding from the analysis capital account openness, which does not extend beyond 2014, we confirm that the positive association holds in longer time series too, and with a higher statistical significance.

${ }^{27}$ In this test, differently from the test in Table 6, factors that load negatively on the BHLS measure (e.g. Investment Profile) are signed such that their forth quantile coincides with periods of high BHLS measure.

${ }^{28}$ There is only evidence of a few increases in regulatory restrictions during financial crises, for example in Malaysia or Iceland.
} 
positive association observed in the data between the VIX Index, which is extensively used as a measure of funding liquidity (Ang et al. (2011)), and the U.S. credit spread is more likely related to the funding channel as opposed to the risk aversion explanation. Similar arguments hold for the negative association between segmentation and decreases in marketwide returns (or market capitalization to GDP). At a monthly frequency, large negative market returns or a decrease in market capitalization to GDP could possibly indicate a worsening of funding liquidity for financial intermediaries instead of deterioration in the financial development of markets, as argued by BHLS. This alternative explanation relies on the observation that most of these intermediaries are net long in the market and capital constraints are more likely to hit during market downturns (Brunnermeier and Pedersen (2009)).

The results of this section suggest that previously studied segmentation factors, which are mainly slow moving processes, can better explain the long-term downward trend in international market segmentation, whereas funding liquidity has stronger explanatory power for the periods of short-term deviations above this trend, i.e. the reversals. In fact, our analysis at higher frequencies enables us to explain the short-term dynamics of the market segmentation and capture some patterns that are more difficult to uncover at the lower frequencies.

\subsection{Segmentation and Local Funding Illiquidity}

In integrated markets, local funding liquidity shocks diversify internationally, by means of global capital mobility. In this case, if a market is hit by a local funding shock, international intermediaries would instantaneously intervene to arbitrage out any mispricing resulting from the shock. On the other hand, in segmented markets, foreign investors are restricted in providing capital, and local funding distress will persist. Therefore, the severity of the financial constraints of the local investors can be an indicator of the magnitude of barriers to investment in that market. That is, we expect to observe larger local funding illiquidity in segmented markets.

To empirically test this hypothesis, first we need to estimate the local funding illiquidity for every market in the cross-section, since these measures are not readily available for large cross-section of countries. As opposed to the U.S. market, data for the TED spread, the broker-dealer balance sheet and implied volatilities are not available in most emerging markets. Similarly, the fixed income-implied measure can only be constructed for a small cross-section of developed markets. ${ }^{29}$ We address the lack of readily available proxies by

\footnotetext{
${ }^{29}$ Malkhozov et al. (2014) construct this measure for a set of six developed markets, with similar method-
} 
estimating a measure of local funding illiquidity from the domestic Margin-CAPM , similar to what is studied in Frazzini and Pedersen (2014) for the U.S. market. In this setting, where there are only investor-specific margins, the expected value of the BAB portfolio equals the shadow price of the margin constraint for the domestic representative investor times the local beta spread. As a result, these BAB portfolios, which are constructed with respect to local market returns, convey the information of funding illiquidity for the local representative investor in each market.

To estimate the local funding illiquidity for each country, we construct the local market neutral BAB portfolio and extract the shadow price of the margin constraint of the local representative investor, $\Psi_{t}^{k}$ with MCMC and Gibbs sampler, controlling only for the local beta spreads. ${ }^{30}$ We acknowledge that this measure of funding liquidity is model-dependent and rejection of this model can lead to mis-specification of the measure. However, there is growing evidence in the literature in support of extracting the funding illiquidity from BAB portfolios. Frazzini and Pedersen (2014) empirically show that in the U.S. market, the shadow price of the margin constraint of the domestic Margin-CAPM is well proxied by the TED spread, as a widely used measure of local funding illiquidity in the U.S. Further empirical evidence can be found in Chen and $\mathrm{Lu}$ (2014) where the authors extract funding liquidity shocks from BAB portfolios using a "difference-in-difference" (DID) approach and show that this measure is correlated with other funding liquidity proxies.

We thus proceed to estimate the local funding liquidities and then use them to study the link with market segmentation, for both the FSI and the BHLS measure. Panel A of Table 8 presents the cross-sectional regression results of the FSI with respect to the local funding shocks, including a set of control variables. These control variables are those that have been shown in the literature to have explanatory power in explaining the cross-section and the dynamics of market segmentation (see Section 4.3). Results in Panel A shows that in all specifications, markets with higher averaged local funding liquidity have larger level of market segmentation, when measured by FSI. Panel B studies this relationship in three subsamples (All markets, Developed markets, and Emerging markets) and corroborates the results in Panel A, confirming that the positive association between market segmentation and local funding illiquidity cuts across all samples. In both developed and emerging markets, we observe that markets with higher average local funding illiquidity are more segmented. Moreover, we observe larger loadings for the emerging markets which imply

ology to Fontaine and Garcia (2012) and Hu et al. (2013).

30 Note that the global funding illiquidity in our previous tests is estimated from the International MarginCAPM, where the betas and the BAB portfolios are estimated with respect to the global market portfolio. Global funding illiquidity $\left(\psi_{t}^{k}\right)$ is then extracted from the BAB portfolios controlling for both country-specific margins and global beta spreads. 
that these markets face relatively higher barriers to free flow of capital. These barriers are likely to prevent the diversification of local funding liquidity shocks.

Results in Panel A and B should be taken with caution as both FSI and $\Psi^{k}$ are estimated in a previous step and are thus prone to error-in-variable bias. To ease such concern, in Panel C we study the relationship between local funding liquidity and segmentation using the BHLS measure of market segmentation. The results in this panel confirm the findings in panels A and B, and bring additional support for the link between the funding liquidity and segmentation. Countries with tighter local funding constraint, as measured by the high average $\Psi^{k}$, are shown to be more segmented from the world. Similar to the results in Panel B, the positive and significant relationship between local funding illiquidity and market segmentation holds in all subsamples.

\section{[Place Table 8 about here]}

Following the results in the previous analysis, we expect to observe a positive association between the time-varying market segmentation and the time-varying intensity of local funding illiquidity. We test this hypothesis in Table 9, which studies market segmentation conditional on local funding illiquidity, in time domain. Similar to Table 8, we study both the FSI and the BHLS measures of market segmentation with respect to the estimated local funding liquidity, $\hat{\Psi}^{k}$, in three subsamples. The results show that for both measures and in all subsamples, market segmentation increases as local funding liquidity dries out. Coefficients of the local funding factor are estimated to be statistically positive for FSI in all subsamples, implying that in periods when investors are more financially constrained segmentation, as indicated by the FSI, is higher. Consistent with previous research, markets with higher regulatory restrictions, larger local market liquidity, poorer investment profile and less developed financial markets (as proxied by local market capitalization to GDP) are more segmented from the rest of the world. Similar to Table 8, in Panel C we ease concerns with respect to error-in-variable bias with the help of the BHLS measure of market segmentation. Panel $\mathrm{C}$ also provides supporting evidence for the positive association between local funding illiquidity and segmentation, documenting that in all subsamples the coefficient estimates for the local funding liquidity are estimated to be positive and significant.

\section{[Place Table 9 about here]}

As an alternative measure of local funding shock, we use local market returns and market capitalization to GDP, that have been also studied in the literature as indicators of 
funding conditions. Brunnermeier and Pedersen (2009) reports that financial intermediaries, as the marginal investors in international markets, are net long in the market portfolio, and as a result capital constraints are more likely to be hit during market downturns. Consistent with this strand of literature, we find that the FSI and the BHLS measure comove negatively with local market returns and market capitalization to GDP, which brings additional support to the link between market segmentation and local funding illiquidity. ${ }^{31}$

Throughout this section, we have acknowledged the error-in-variable bias in the results reported in tables 8 and 9. To further confirm that the main results of this section are not qualitatively affected by such bias, in Table 10 we focus on the U.S. market. We choose the U.S. market because of the large population of active international institutional investors residing in the U.S. and data availability necessary to construct multiple measures of funding liquidity. The table shows that for both indicators of market segmentation, the FSI and the BHLS measure, we observe higher U.S. market segmentation as the funding condition in the U.S. economy worsen. Using the FSI as dependent variable, the broker-dealer's total asset and leverage, and the TED spread are estimated to be positive and significant while the VIX index and the fixed income-implied funding liquidity are also estimated to be positive but at a lower statistical significance. For the BHLS measure, we similarly observe a positive association between the U.S. market segmentation and funding conditions with positive and almost in all cases significant coefficients. In untabulated results, we also find supportive evidence for reversals with quantile regressions, using the U.S. as the test asset with FSI and the BHLS measure of the U.S. increasing in tight funding periods and decreasing in relaxed periods. This is consistent with the hypothesis that affluent arbitrageurs, during the relaxed funding periods, trade more intensively internationally and close price gaps across markets.

\section{[Place Table 10 about here]}

The evidence documented in this section is aligned with the research on international banks' lending behavior (see Holmstrom and Tirole (1997), Morgan, Rime, and Strahan (2004), Kalemli-Ozcan, Papaioannou, and Peydró (2013)). This strand of literature argues that if firms in a certain country are hit by unfavorable shocks to their collateral, banks rebalance their lending in order to decrease lending in this country and increase lending in the non-affected countries. This contributes to further disconnect the affected country from the rest of the world.

\footnotetext{
${ }^{31}$ Results are available upon request.
} 


\section{Conclusion}

This paper links the literature on limits to arbitrage and intermediary asset pricing with the international finance literature and offers an explanation for reversals in international market integration via the role of institutional investors and funding liquidity.

We show that during global funding distress, betting against beta portfolios (the BAB factors), which load on funding illiquidity, comove less across markets. Inspired by these findings, we study the segmentation implications of an International Margin-CAPM that incorporates borrowing frictions of investors in international markets. The proposed model is an extension of Frazzini and Pedersen (2014)'s model to the international setting by means of country-specific and investor-specific margins. In the context of the model where margins are time varying, constraints also vary through time. Periods when funding constraints of intermediaries are not binding correspond to higher integration among international financial markets. Periods of tightening constraints that follow relaxed ones, correspond to reversals and increase in segmentation among countries.

A Funding-implied Segmentation Indicator (FSI), extracted from countries' BAB portfolios not only fits the previously documented evidence of market segmentation but also explains reversals in market integration during global funding shocks. We argue that withholding investments by global investors in certain markets during periods of tight funding constraints, as implied by the FSI, is consistent with the "flight home" effect and the deviations from the Law of One Price documented in other literature. Moreover, we show that markets that experience more severe local funding shocks are on average more segmented. This is consistent with the notion that local funding shocks which persist where the access of intermediary capital is somewhat restricted, lead to inefficient risk sharing, as more local risk will be borne by local investors.

Previous research has explained cross-sectional differences and time-variation in integration across countries through the presence of barriers to foreign investment. However, there is no a priori expectation to observe increases in the severity of such barriers that would be necessary to explain reversals in integration during crisis periods. In fact, em-

pirically, most of these barriers are slow-moving processes that are a better explanation of the long-term dynamics of international market integration than its short-term reversals. We argue that the funding channel provides a plausible explanation for reversals. This channel adds a new dimension to the understanding of the dynamics of international market integration especially in the post-liberalization period, when most explicit barriers to foreign investment have been eliminated. 


\section{References}

Adrian, T., T. Muir, and E. Etula. 2014. Financial Intermediaries and the Cross-Section of Asset Returns. The Journal of Finance .

Adrian, T., and H. S. Shin. 2010. Liquidity and leverage. Journal of Financial Intermediation 19:418-437.

Adrian, T., and H. S. Shin. 2014. Procyclical Leverage and Value-at-Risk. Review of Financial Studies 27:373-403.

Ang, A., and J. Chen. 2007. CAPM over the long run: 1926-2001. Journal of Empirical Finance 14:1-40.

Ang, A., S. Gorovyy, and G. B. van Inwegen. 2011. Hedge fund leverage. Journal of Financial Economics 102:102-126.

Antoniou, C., J. A. Doukas, and A. Subrahmanyam. 2014. Investor Sentiment, Beta, and the Cost of Equity Capital. Managment Science forthcoming.

Ashcraft, A., N. Gârleanu, and L. H. Pedersen. 2011. Two Monetary Tools: Interest Rates and Haircuts. NBER Macroeconomics Annual 25.

Baker, M., B. Bradley, and J. Wurgler. 2010. Benchmarks as Limits to Arbitrage: Understanding the Low-Volatility Anomaly. Financial Analysts Journal 67:40-54.

Bali, T. G., S. Brown, S. Murray, and Y. Tang. 2014. Betting Against Beta or Demand for Lottery. SSRN Scholarly Paper ID 2408146, Social Science Research Network, Rochester, NY.

Basak, S., and B. Croitoru. 2000. Equilibrium mispricing in a capital market with portfolio constraints. Review of Financial Studies 13:715-748.

Bekaert, G., and C. R. Harvey. 1995. Time-Varying World Market Integration. The Journal of Finance 50:403-444.

Bekaert, G., C. R. Harvey, and C. Lundblad. 2007. Liquidity and Expected Returns: Lessons from Emerging Markets. Review of Financial Studies 20:1783-1831.

Bekaert, G., C. R. Harvey, C. T. Lundblad, and S. Siegel. 2011. What Segments Equity Markets? Review of Financial Studies 24:3841-3890.

Bekaert, G., C. R. Harvey, C. T. Lundblad, and S. Siegel. 2013. The European Union, the Euro, and equity market integration. Journal of Financial Economics 109:583-603.

Bekaert, G., C. R. Harvey, C. T. Lundblad, and S. Siegel. 2014. Stock Market Valuations Across U.S. States.

Black, F. 1972. Capital Market Equilibrium with Restricted Borrowing. The Journal of Business 45:444-455. 
Black, F. 1974. International capital market equilibrium with investment barriers. Journal of Financial Economics 1:337-352.

Boguth, O., and M. Simutin. 2015. Leverage Constraints and Asset Prices: Insights from Mutual Fund Risk Taking. Tech. Rep. working paper.

Brennan, M. J., X. Cheng, and F. Li. 2012. Agency and Institutional Investment. European Financial Management 18:1-27.

Brunnermeier, M. K., and L. H. Pedersen. 2009. Market Liquidity and Funding Liquidity. Review of Financial Studies 22:2201-2238.

Buss, A., and G. Vilkov. 2012. Measuring Equity Risk with Option-implied Correlations. Review of Financial Studies 25:3113-3140.

Campbell, J. Y., S. Giglio, C. Polk, and R. Turley. 2012. An Intertemporal CAPM with Stochastic Volatility. Working Paper 18411, National Bureau of Economic Research.

Carrieri, F., I. Chaieb, and V. Errunza. 2013. Do Implicit Barriers Matter for Globalization? Review of Financial Studies 26:1694-1739.

Carrieri, F., V. Errunza, and K. Hogan. 2007. Characterizing World Market Integration through Time. The Journal of Financial and Quantitative Analysis 42:915-940.

Chabakauri, G. 2013. Dynamic Equilibrium with Two Stocks, Heterogeneous Investors, and Portfolio Constraints. Review of Financial Studies 26:3104-3141.

Chen, Z., and P. J. Knez. 1995. Measurement of market integration and arbitrage. Review of Financial Studies 8:287-325.

Chen, Z., and A. Lu. 2014. A Market-Based Funding Liquidity Measure. Tech. Rep. working paper.

Coeurdacier, C., and H. Rey. 2013. Home Bias in Open Economy Financial Macroeconomics. Journal of Economic Literature 51.

Duffie, D. 2010. Presidential Address: Asset Price Dynamics with Slow-Moving Capital. The Journal of Finance 65:1237-1267.

Duffie, D., and B. Strulovici. 2012. Capital Mobility and Asset Pricing. Econometrica 80:2469-2509.

Eiling, E., and B. Gerard. 2014. Emerging Equity Market Comovements: Trends and MacroEconomic Fundamentals. Review of Finance-forthcoming .

Engle, R. 2002. Dynamic Conditional Correlation: A Simple Class of Multivariate Generalized Autoregressive Conditional Heteroskedasticity Models. Journal of Business \& Economic Statistics 20:339-350. 
Errunza, V., and E. Losq. 1985. International Asset Pricing under Mild Segmentation: Theory and Test. The Journal of Finance 40:105-124.

Fleckenstein, M., F. A. Longstaff, and H. Lustig. 2014. The TIPS-Treasury Bond Puzzle. The Journal of Finance 69:2151-2197.

Fontaine, J.-S., and R. Garcia. 2012. Bond Liquidity Premia. Review of Financial Studies 25:1207-1254.

Fostel, A., and J. Geanakoplos. 2008. Leverage Cycles and the Anxious Economy. American Economic Review 98:1211-1244.

Fostel, A., and J. Geanakoplos. 2013. Reviewing the Leverage Cycle. Tech. Rep. Working Paper.

Frazzini, A., and L. H. Pedersen. 2014. Betting against beta. Journal of Financial Economics 111:1-25.

Gârleanu, N., and L. H. Pedersen. 2011. Margin-based Asset Pricing and Deviations from the Law of One Price. Review of Financial Studies 24:1980-2022.

Geanakoplos, J. 2010. The Leverage Cycle. NBER Macroeconomics Annual 24:213-233.

Giannetti, M., and L. Laeven. 2012. Flight Home, Flight Abroad, and International Credit Cycles. The American Economic Review 102:219-224.

Giannetti, M., and L. Laeven. 2015. Local Ownership, Crises, and Asset Prices: Evidence from US Mutual Funds. Review of Finance forthcoming.

Gorton, G. B., and A. Metrick. 2010. Haircuts. Tech. Rep. working paper.

Goyenko, R., and S. Sarkissian. 2014. Treasury Bond Illiquidity and Global Equity Returns. Journal of Financial and Quantitative Analysis 49:1227-1253.

Gromb, D., and D. Vayanos. 2002. Equilibrium and welfare in markets with financially constrained arbitrageurs. Journal of Financial Economics 66:361-407.

Gârleanu, N., S. Panageas, and J. Yu. 2015. Financial Entanglement: A Theory of Incomplete Integration, Leverage, Crashes, and Contagion. The American Economic Review 105:1979-2010.

Hameed, A., W. Kang, and S. Viswanathan. 2010. Stock Market Declines and Liquidity. The Journal of Finance 65:257-293.

He, Z., and A. Krishnamurthy. 2012. A Model of Capital and Crises. The Review of Economic Studies 79:735-777.

He, Z., and A. Krishnamurthy. 2013. Intermediary Asset Pricing. The American Economic Review 103:732-770. 
Hoggarth, G., L. Mahadeva, and J. H. Martin. 2010. Understanding International Bank Capital Flows During the Recent Financial Crisis. Tech. rep., Financial Satability Paper No. 8, Bank of England.

Holmstrom, B., and J. Tirole. 1997. Financial Intermediation, Loanable Funds, and The Real Sector. The Quarterly Journal of Economics 112:663-691.

Hong, H. G., and D. A. Sraer. 2015. Speculative Betas. Journal of Finance forthcoming.

Hu, G. X., J. Pan, and J. Wang. 2013. Noise as Information for Illiquidity. The Journal of Finance 68:2341-2382.

Huang, S., D. Lou, and C. Polk. 2014. The Booms and Busts of Beta Arbitrage .

Jostova, G., and A. Philipov. 2005. Bayesian Analysis of Stochastic Betas. Journal of Financial and Quantitative Analysis 40:747-778.

Jotikasthira, C., C. Lundblad, and T. Ramadorai. 2012. Asset Fire Sales and Purchases and the International Transmission of Funding Shocks. The Journal of Finance 67:20152050 .

Jurek, J. W., and E. Stafford. 2010. Haircut dynamics. Working Paper.

Kalemli-Ozcan, S., E. Papaioannou, and J.-L. Peydró. 2013. Financial Regulation, Financial Globalization, and the Synchronization of Economic Activity. The Journal of Finance 68:1179-1228.

Karolyi, G. A., K.-H. Lee, and M. A. van Dijk. 2012. Understanding commonality in liquidity around the world. Journal of Financial Economics 105:82-112.

Lee, K.-H. 2011. The world price of liquidity risk. Journal of Financial Economics 99:136161.

Lehkonen, H. 2014. Stock Market Integration and the Global Financial Crisis. Review of Finance p. rfu039.

Lewellen, J., and S. Nagel. 2006. The conditional CAPM does not explain asset-pricing anomalies. Journal of Financial Economics 82:289-314.

Longin, F., and B. Solnik. 2001. Extreme Correlation of International Equity Markets. The Journal of Finance 56:649-676.

Malkhozov, A., P. Mueller, A. Vedolin, and G. Venter. 2014. Funding Liquidity CAPM: International Evidence. Tech. Rep. working paper.

Morgan, D. P., B. Rime, and P. E. Strahan. 2004. Bank Integration and State Business Cycles. The Quarterly Journal of Economics 119:1555-1584.

Newey, W. K., and K. D. West. 1987. A Simple, Positive Semi-Definite, Heteroskedasticity and Autocorrelation Consistent Covariance Matrix. Econometrica 55:703-708. 
Pasquariello, P. 2014. Financial Market Dislocations. Review of Financial Studies 27:18681914.

Petersen, M. A. 2009. Estimating Standard Errors in Finance Panel Data Sets: Comparing Approaches. The Review of Financial Studies 22:435-480.

Pontiff, J. 2006. Costly arbitrage and the myth of idiosyncratic risk. Journal of Accounting and Economics 42:35-52.

Pukthuanthong, K., and R. Roll. 2009. Global market integration: An alternative measure and its application. Journal of Financial Economics 94:214-232.

Rey, H. 2015. Dilemma not Trilemma: The global Financial Cycle and Monetary Policy Independence .

Rytchkov, O. 2014. Asset Pricing with Dynamic Margin Constraints. The Journal of Finance 69:405-452.

Shleifer, A., and R. W. Vishny. 1997. The Limits of Arbitrage. The Journal of Finance 52:35-55.

Stulz, R. M. 1981. On the Effects of Barriers to International Investment. The Journal of Finance 36:923-934.

Warnock, F. E., and V. C. Warnock. 2009. International capital flows and U.S. interest rates. Journal of International Money and Finance 28:903-919. 


\section{Appendix}

\section{A Mean-Variance Optimization}

Investors optimize the following utility subject to margin constraints.

$$
\begin{array}{lrl}
\max _{\mathrm{x}_{\mathrm{i}, \mathrm{t}}} x_{i, t}^{\top}\left(E_{t}\left[P_{t+1}+D_{t+1}\right]-\left(1+r^{f}\right) P_{t}\right)-\frac{\gamma_{i}}{2} x_{i, t}^{\top} \Omega_{t} x_{i, t} \\
\sum_{j} m_{i, t}^{k} x_{i, t}^{j} P_{t}^{j} \leq W_{i, t}, & \forall j \in k
\end{array}
$$

Under the null hypothesis of market integration, a subgroup of investors cannot face higher margin requirements for a subgroup of assets, that is we have $m_{i, t}^{k}=m_{i, t} m_{t}^{k}$ for all asset $j$ in country $k$. In equilibrium, market clears, i.e. $\sum_{i} x_{i, t}^{j}=\theta_{t}^{j}$. Therefore, first order condition of the above optimization problem results in:

$$
\mathrm{FOC}: 0=E_{t}\left[P_{t+1}+D_{t+1}\right]-\left(1+r^{f}\right) P_{t}-\gamma_{i} \Omega_{t} x_{i, t}-\psi_{i, t} M_{i, t}
$$

Where $\psi_{i, t}$ is the shadow price of the margin constraint for the agent $i$ (Equation (10)) and $M_{i, t}=\left(m_{i, t}^{1} P_{i}^{1}, \ldots, m_{i, t}^{K} P_{i}^{J}\right)$ is a vector of dollar margins for holdings of this agent. Rearranging Equation (11), we have the portfolio choice of investor $i$ :

$$
x_{i, t}=\frac{1}{\gamma_{i}} \Omega_{t}^{-1}\left(E_{t}\left[P_{t+1}+D_{t+1}\right]-\left(1+r^{f}\right) P_{t}-\psi_{i, t} M_{i, t}\right)
$$

In equilibrium market clears. Aggregating asset demands for asset $j$ over all investors, $i$, and rearrangement of Equation (12) we get the price of asset $j$ :

$$
P_{t}^{j}=\frac{E_{t}\left[P_{t+1}+D_{t+1}\right]-\gamma 1_{j}^{\top} \Omega_{t} \theta_{t}}{1+r^{f}+\psi_{t} m_{t}^{k}}, \quad \forall j \in k
$$

Where $1_{j}^{\top}$ is a $J \times 1$ vector of zeros with one in column $j, \frac{1}{\gamma}=\sum_{i} \frac{1}{\gamma_{i}}$ and $\psi_{t}=\sum_{i} \frac{\gamma}{\gamma_{i}} \psi_{i, t} m_{i, t}$ are the coefficient of risk aversion and the shadow price of the margin constraint for the representative agent. Thus, the expected return of asset $j$ follows:

$$
E_{t}\left[r_{t+1}^{j}\right]=\frac{E_{t}\left[P_{t+1}^{j}+D_{t+1}^{j}\right]}{P_{t}^{j}}-1=r^{f}+\psi_{t} m_{t}^{k}+\gamma \frac{1}{P_{t}^{j}} 1_{j}^{\top} \Omega_{t} \theta_{t}, \quad \forall j \in k
$$


Labeling global market return $r^{G}$ and expanding the covariance matrix, we have:

$$
\frac{1}{P_{t}^{j}} 1_{j}^{\top} \Omega_{t} \theta_{t}=\frac{1}{P_{t}^{j}} \operatorname{cov}_{t}\left(P_{t+1}^{j}+D_{t+1}^{j}, \theta_{t}^{\top}\left[P_{t+1}+D_{t+1}\right]\right)=\operatorname{cov}_{t}\left(r_{t+1}^{j}, r_{t+1}^{G}\right) \theta_{t}^{\top} P_{t}
$$

So, Equation (14) simplifies to

$$
E_{t}\left[r_{t+1}^{j}\right]=r^{f}+\psi_{t} m_{t}^{k}+\gamma \operatorname{cov}_{t}\left(r_{t+1}^{j}, r_{t+1}^{G}\right) \theta_{t}^{\top} P_{t}, \quad \forall j \in k
$$

Aggregating Equation (16) by market portfolio weights, i.e. $\frac{\theta_{t}^{j} P_{t}^{j}}{\sum_{j} \theta_{t}^{j} P_{t}^{j}}$, and choosing $m^{G}=$ $\sum_{j} m^{k} \frac{\theta^{j} P^{j}}{\sum_{j} \theta^{j} P^{j}}$ we obtain

$$
E_{t}\left[r_{t+1}^{G}\right]=r^{f}+\psi_{t} m_{t}^{G}+\gamma \operatorname{var}_{t}\left(r_{t+1}^{G}\right) \theta_{t}^{\top} P_{t}
$$

Define the market risk premium $\lambda_{t}=E_{t}\left[r_{t+1}^{G}\right]-r^{f}$ and $\beta_{j, t}=\frac{\operatorname{cov}_{t}\left(r_{t+1}^{j}, r_{t+1}^{G}\right)}{\operatorname{var}_{t}\left(r_{t+1}^{G}\right)}$, and substitute Equation (17) into Equation (16), we have the International Margin-CAPM:

$$
E_{t}\left[r_{t+1}^{j}\right]-r^{f}=\beta_{t}^{j} \lambda_{t}+\psi_{t}\left(m_{t}^{k}-\beta_{t}^{j} m_{t}^{G}\right), \quad \forall j \in k
$$

Now if we form beta neutral portfolio, then Equation (18) implies the expected return of this portfolio is related to the beta spread in that market, shadow price of the funding constraint of representative agent and market specific margins. To form the BAB portfolio, $r_{B A B}$, in each market $k$ we long local low beta portfolio, $r_{H}$, levered to beta one and short local high beta portfolio, $r_{L}$, delevered to beta one.

$$
\begin{aligned}
E_{t}\left[r_{B A B, t+1}^{k}\right]-r^{f} & =\frac{1}{\beta_{L, t}^{k}}\left(r_{L, t}^{k}-r^{f}\right)-\frac{1}{\beta_{H, t}^{k}}\left(r_{H, t}^{k}-r^{f}\right) \\
& =\frac{\beta_{H, t}^{k}-\beta_{L, t}^{k}}{\beta_{H, t}^{k} \beta_{L, t}^{k}} \psi_{t} m_{t}^{k}
\end{aligned}
$$

\section{B Mild Segmentation}

The setting in Equation 9 fully nests traditional barriers to investments as discussed in the international finance literature; if an asset in a country $k$ is totally inaccessible to investor $i$, then the required margin for that asset from investor $i$ is infinite. ${ }^{32}$ Formally, in a fully segmented world we have $m_{i}^{j}=\kappa_{i}^{k} m_{i} m^{j}$; where $\kappa_{i}^{k}$ is equal to one if investor $i$ resides in country $k$ and is infinite otherwise. This discontinuity in margins across markets results in multiple pricing kernels, therefore, this formulation matches the textbook definition of

\footnotetext{
${ }^{32}$ See Black (1974) and Stulz (1981) for similar argument with infinite taxes.
} 
segmented world where assets of each market are priced by a different pricing kernel, and consequently local factors, as opposed to global factors, price local assets. Similarly, cases of mild segmentation, where part of the local investment opportunity set is accessible to foreign investors assets, or where foreign investors face higher costs to international investments are attainable in this setting by proper choice of $\kappa$. Consequently, with any non-infinite (finite) value of $\kappa$ for foreign investors, local and global factors jointly price local assets together, as in Errunza and Losq (1985). In a segmented world, there is no representative investor and both local and global factors price assets. In fact, it can be shown that with barriers to investment (i.e. $\kappa_{i}^{k} \neq 1$ ) we have segmented markets:

$$
E_{t}\left[r_{t+1}^{j}\right]-r^{f}=\beta_{t}^{j} \lambda_{t}+\phi_{t}^{k}-\beta_{t}^{j} \phi_{t}^{G}
$$

where, $\phi_{t}^{k}=f\left(\kappa_{i}^{k}\right)$ is a market-specific factor that captures investors funding constraints for investing in assets in country $k$, and $\phi_{t}^{G}$ is a global factor that captures the aggregate funding constraints of the investors across markets.

\section{BAB Portfolio}

We follow Frazzini and Pedersen's methodology in estimating BAB portfolios. For this purpose, we compute beta of each asset by estimating volatilities and correlations separately:

$$
\beta_{j}^{T S}=\widehat{\rho_{j m}} \widehat{\widehat{\sigma_{j}}}
$$

Beta of asset $j$ at each period is computed by the correlation of this asset and the global market portfolio in the last five years, multiplied by the ratio of asset volatility to market volatility, in the last year. Since correlations appear to move more slowly than volatilities, a smaller window is assigned for volatility estimation. For volatility estimation, we use one-day log returns and use overlapping three-day log returns for correlation estimation to control for nonsynchronous trading. Moreover, at least 120 trading days of non-missing data is required to estimate volatilities. Similarly at least 750 trading days of non-missing return data is required for correlations estimation. After calculating the betas, they are shrunk toward the cross-sectional mean (i.e. 1 ) to reduce the influence of outliers: $\beta_{j}=$ $0.6 \beta_{j}^{T S}+0.4$.

To form the BAB portfolio, at each period, assets are ranked based on their ex-ante betas in ascending order and grouped in two categories (high- and low-beta) based on the median of the betas. In each portfolio, securities are weighted by the ranked betas (i.e., lower-beta securities have larger weights in the low-beta portfolio and higher-beta 
securities have larger weights in the high-beta portfolio). The portfolios are rebalanced every calendar month. BAB is then formed by longing the high beta portfolio, de-leveraged to beta one, and shorting the low beta portfolio, leveraged to a beta of one. This results in a zero beta portfolio, ex-ante. More formally if $\boldsymbol{r}_{t}^{\top}$ is the vector of monthly asset returns and $\boldsymbol{\beta}_{t}^{\top}$ we have:

1. $r_{H, t+1}=\boldsymbol{r}_{t+1}^{\top} \boldsymbol{w}_{\boldsymbol{H}, t}$, and $r_{L, t+1}=\boldsymbol{r}_{t+1}^{\top} \boldsymbol{w}_{L, t}$.

2. $\beta_{H, t+1}=\boldsymbol{\beta}_{t+1}^{\top} \boldsymbol{w}_{\boldsymbol{H}, t}$, and $\beta_{L, t+1}=\boldsymbol{\beta}_{t+1}^{\top} \boldsymbol{w}_{L, t}$.

3. $r_{B A B, t+1}=\frac{1}{\beta_{L, t}}\left(r_{L, t+1}-r^{f}\right)-\frac{1}{\beta_{H, t}}\left(r_{H, t+1}-r^{f}\right)$

\section{MCMC and Gibbs Sampler}

In this paper, we implement Markov Chain Monte Carlo (MCMC) and Gibbs sampler to draw samples from the conditional distributions, following Jostova and Philipov (2005) and Ang and Chen (2007), who implement a similar methodology to estimate conditional beta of a single-factor CAPM. The Bayesian estimation includes the following steps. First we impose a dynamic for the global funding liquidity, $\psi_{t}$ (See Equation 23). Then we choose prior distributions for the model parameters. Here, we assume the joint prior distribution is the product of the independent priors of each unknown parameter. Then, the likelihood function is derived from the dynamics of the BAB returns and the shadow price of the funding constraints (see below). By Bayes's Law, we find the posterior distributions and the conditional posterior distributions for each parameter given the rest of the unknown parameters. In the last step, we draw random samples from these conditional posterior distributions and take the averages of these samples, to obtain the expected value of the joint distribution of the unknown parameters.

$$
\begin{aligned}
r_{B A B, t+1} & =\psi_{t} \hat{Z}_{t}+\sigma_{b} \varepsilon_{t} \\
\psi_{t} & =\phi_{0}+\phi_{1}\left(\psi_{t-1}-\phi_{0}\right)+\sigma_{\psi} \epsilon_{t}
\end{aligned}
$$

The unknown parameters are $\phi_{0}, \phi_{1}, \sigma_{\psi}, \sigma_{b}$. Since $\psi_{t}$ is a persistent variable, here we assume it follows a stationary AR(1) process with unconditional mean $\phi_{0}$ and mean reversion speed $\phi_{1}$. For $\phi_{0}$, we choose a normal prior with mean $\hat{\psi}$ and standard deviation 10. $\hat{\psi}$ is the OLS estimate of $\psi_{t}$, assuming time-invariant process in Equation (23). For $\phi_{1}$, we consider a truncated normal prior with mean 0.5 and standard deviation 10 that lies in the interval $(-1,1)$. This range of values for $\phi_{1}$ ensures stationarity of $\psi_{t}$. For the variance of 
the shadow price of the funding constraint, $\sigma_{\psi}$, I suggest an inverse gamma (IG) prior (typically used in the literature to model the distribution of unknown variances) with shape and scale parameters equal to 0.001. Similarly, for the variance of the BAB returns, $\sigma_{b}$, we select an IG prior with shape and scale parameters equal to 0.001 . Based on the above dynamics and assumptions, $\psi_{t}$ and $\mathrm{BAB}$ returns follow conditional normal distributions:

$$
\begin{aligned}
\psi_{t} \mid \psi_{t-1} & \sim \mathcal{N}\left(\phi_{0}+\phi_{1}\left(\psi_{t-1}-\phi_{0}\right), \sigma_{\psi}^{2}\right) \\
r_{B A B, t} \mid \psi_{t}, Z_{t} & \sim \mathcal{N}\left(\psi_{t} Z_{t}, \sigma_{b}^{2}\right)
\end{aligned}
$$

Therefore, the likelihood function is:

$$
L\left(\boldsymbol{\psi}, \phi_{0}, \phi_{1}, \sigma_{\psi}, \sigma_{b} \mid \mathbf{r}_{\mathbf{B A B}}, \mathbf{Z}\right) \propto \prod_{t=1}^{T} \mathcal{N}\left(\phi_{0}+\phi_{1}\left(\psi_{t-1}-\phi_{0}\right), \sigma_{\psi}^{2}\right) \times \prod_{t=1}^{T} \mathcal{N}\left(\psi_{t} Z_{t}, \sigma_{b}^{2}\right)
$$

where, $\boldsymbol{\psi}=\left[\psi_{1}, \ldots, \psi_{T}\right], \quad \mathbf{r}_{\mathrm{BAB}}=\left[r_{B A B, 1}, \ldots, r_{B A B, T}\right]$, and $\mathbf{Z}=\left[Z_{1}, \ldots, Z_{T}\right]$. By Bayes' Law we have that the Posterior Distribution, $p(\boldsymbol{\theta} \mid \boldsymbol{y})$, is proportional to the prior distribution times the likelihood function. Formally, $p(\boldsymbol{\theta} \mid \boldsymbol{y}) \propto p\left(\phi_{0}, \phi_{1}, \sigma_{\psi}, \sigma_{b}\right) \times L(\boldsymbol{\theta} \mid \boldsymbol{y})$, where, $\boldsymbol{\theta}$ is defined as a vector of $\left(\boldsymbol{\psi}, \phi_{0}, \phi_{1}, \sigma_{\psi}, \sigma_{b}\right)^{\top}$ and $\boldsymbol{y}$ is the vector of $\left(\mathbf{r}_{\mathbf{B A B}}, \mathbf{Z}\right)^{\top}$. Since the prior distribution is not a well-defined joint distribution, we implement the Gibbs Sampler which enables us to draw samples from the conditional posterior distributions, $p\left(\theta_{k} \mid\right.$ rest $)$, instead. In each iteration $i=1, \cdots, I$ of the Gibbs Sampler, and for each model parameter $k=1, \cdots, K$ we draw samples iteratively from the conditional prior distributions. More specifically, we draw the current sample of $\theta_{k}$ conditional on the current samples of $\theta_{1}, \cdots, \theta_{k-1}$ and the previous samples of $\theta_{k+1}, \cdots, \theta_{K}$, where $K$ is the number of unknown parameters.

$$
p\left(\theta_{k}^{(i+1)} \mid \theta_{1}^{(i+1)}, \cdots, \theta_{k}^{(i+1)}, \theta_{k+1}^{(i)}, \cdots, \theta_{K}^{(i)}, \boldsymbol{y}\right)
$$

We randomly draw 10,000 samples from the posteriors and exclude the first 1,000 draws, since they are considered as the startup phase. 


\section{Figures and Tables}

\section{A Tables}

Table 1. Summary Statistics of BAB portfolios

\begin{tabular}{|c|c|c|c|c|c|c|}
\hline Country & $\mathrm{EM} / \mathrm{DM}$ & \#Firms & $\overline{\text { R.Vol.\% }}$ & $\overline{r_{B A B} \%}$ & $\overline{\beta \text { Spread }}$ & $\rho\left(r_{B A B}^{k}, r_{B A B}^{U S}\right)$ \\
\hline Argentina & EM & 107 & 6.38 & 0.20 & 0.38 & 0.14 \\
\hline Australia & DM & 2525 & 4.88 & 1.28 & 0.77 & 0.18 \\
\hline Austria & DM & 161 & 4.11 & 0.82 & 0.44 & 0.06 \\
\hline Bahrain & EM & 38 & 2.67 & 10.00 & 0.74 & 0.12 \\
\hline Belgium & DM & 243 & 4.20 & 0.82 & 0.53 & 0.23 \\
\hline Brazil & EM & 258 & 7.33 & 0.92 & 0.39 & 0.03 \\
\hline Bulgaria & EM & 230 & 5.92 & 2.41 & 0.51 & -0.04 \\
\hline Canada & DM & 3815 & 3.62 & 0.88 & 0.80 & 0.36 \\
\hline Chile & EM & 258 & 4.31 & 0.04 & 0.74 & 0.08 \\
\hline China & EM & 2578 & 7.00 & -0.01 & 1.12 & -0.06 \\
\hline Colombia & EM & 81 & 4.80 & -0.87 & 0.23 & 0.13 \\
\hline Croatia & EM & 112 & 4.66 & 1.52 & 0.41 & -0.37 \\
\hline Cyprus & EM & 109 & 7.22 & -7.52 & 0.61 & 0.10 \\
\hline Czech Republic & EM & 85 & 5.84 & 3.42 & 0.95 & 0.07 \\
\hline Denmark & DM & 312 & 4.61 & 0.73 & 0.49 & 0.21 \\
\hline Egypt & EM & 128 & 5.47 & 0.76 & 0.78 & 0.04 \\
\hline Finland & DM & 203 & 6.66 & 0.66 & 0.57 & 0.23 \\
\hline France & DM & 1599 & 4.81 & 0.76 & 0.55 & 0.32 \\
\hline Germany & DM & 1390 & 4.56 & 0.76 & 0.61 & 0.33 \\
\hline Greece & EM & 374 & 6.92 & 0.28 & 0.51 & 0.03 \\
\hline Hong Kong & DM & 1078 & 5.73 & 0.48 & 0.55 & 0.19 \\
\hline Hungary & EM & 62 & 7.12 & 0.82 & 0.43 & 0.16 \\
\hline India & EM & 2672 & 5.98 & 0.49 & 0.95 & 0.09 \\
\hline Indonesia & EM & 538 & 7.02 & 0.54 & 0.43 & 0.08 \\
\hline Ireland & DM & 104 & 4.87 & 0.33 & 0.75 & 0.09 \\
\hline Israel & EM & 487 & 5.35 & 0.60 & 0.59 & 0.02 \\
\hline Italy & DM & 506 & 5.58 & 0.60 & 0.51 & 0.23 \\
\hline Japan & DM & 4823 & 4.99 & 0.73 & 0.55 & 0.16 \\
\hline Jordan & EM & 151 & 2.88 & -0.19 & 0.72 & 0.15 \\
\hline Kuwait & EM & 131 & 3.50 & -3.09 & 0.63 & 0.22 \\
\hline Luxembourg & DM & 50 & 4.34 & 2.10 & 0.78 & -0.04 \\
\hline & & & & & \multicolumn{2}{|c|}{ Continued on next page } \\
\hline
\end{tabular}


Table 1 - continued from previous page

\begin{tabular}{|c|c|c|c|c|c|c|}
\hline Country & EM/DM & \#Firms & $\overline{R . V o l . \%}$ & $\overline{r_{B A B} \%}$ & $\overline{\beta \text { Spread }}$ & $\rho\left(r_{B A B}^{k}, r_{B A B}^{U S}\right)$ \\
\hline Malaysia & EM & 1178 & 4.19 & 0.83 & 0.57 & 0.15 \\
\hline Malta & EM & 16 & 3.90 & -2.82 & 0.63 & 0.19 \\
\hline Mexico & EM & 207 & 5.77 & 0.86 & 0.86 & 0.00 \\
\hline Morocco & EM & 79 & 3.52 & 1.28 & 0.57 & 0.09 \\
\hline Netherlands & $\mathrm{DM}$ & 293 & 4.13 & 1.25 & 0.52 & 0.37 \\
\hline New Zealand & $\mathrm{DM}$ & 200 & 4.47 & 0.91 & 0.44 & 0.11 \\
\hline Nigeria & EM & 112 & 3.49 & 2.74 & 0.84 & -0.18 \\
\hline Norway & $\mathrm{DM}$ & 437 & 5.86 & 0.93 & 0.53 & 0.16 \\
\hline Oman & EM & 105 & 2.15 & 1.05 & 0.60 & -0.28 \\
\hline Pakistan & EM & 210 & 5.90 & 1.03 & 0.85 & 0.01 \\
\hline Peru & EM & 168 & 3.85 & 1.84 & 1.43 & 0.01 \\
\hline Philippines & EM & 241 & 5.32 & 0.49 & 0.46 & 0.11 \\
\hline Poland & EM & 541 & 7.06 & 0.89 & 0.42 & 0.12 \\
\hline Portugal & EM & 132 & 4.68 & 0.49 & 0.71 & 0.02 \\
\hline Qatar & EM & 37 & 4.00 & 0.18 & 0.49 & 0.09 \\
\hline Romania & EM & 142 & 7.34 & 2.65 & 0.49 & 0.05 \\
\hline Russian Federation & EM & 500 & 7.61 & 1.40 & 0.60 & 0.36 \\
\hline Singapore & DM & 811 & 4.57 & 0.95 & 0.55 & 0.10 \\
\hline Slovenia & EM & 58 & 4.36 & 0.94 & 0.46 & 0.12 \\
\hline South Africa & EM & 681 & 6.04 & 0.53 & 0.67 & 0.07 \\
\hline South Korea & EM & 2116 & 7.10 & 0.51 & 0.59 & 0.08 \\
\hline Spain & $\mathrm{DM}$ & 270 & 5.01 & 0.85 & 0.60 & 0.27 \\
\hline Sri Lanka & EM & 221 & 3.83 & 0.47 & 1.01 & -0.01 \\
\hline Sweden & $\mathrm{DM}$ & 703 & 5.65 & 1.23 & 0.49 & 0.40 \\
\hline Switzerland & $\mathrm{DM}$ & 372 & 4.07 & 0.87 & 0.63 & 0.23 \\
\hline Taiwan & EM & 1914 & 6.45 & -0.22 & 0.52 & 0.24 \\
\hline Thailand & EM & 698 & 6.70 & 0.19 & 0.77 & 0.09 \\
\hline Turkey & EM & 386 & 11.03 & 0.01 & 0.42 & 0.07 \\
\hline United Kingdom & $\mathrm{DM}$ & 3916 & 4.60 & 0.82 & 0.59 & 0.44 \\
\hline United States & $\mathrm{DM}$ & 16406 & 3.58 & 0.79 & 0.67 & 1.00 \\
\hline Venezuela & EM & 47 & 6.80 & 9.14 & 0.91 & 0.03 \\
\hline
\end{tabular}

The table presents descriptive statistics for the Betting-Against-Beta (BAB) portfolios constructed from securities in each market. The sample includes 25 developed markets, identified with DM, and 37 emerging market, identified with EM, from 1973 to 2014 (Data source: DataStream). The table reports the number of firms in each market, average monthly realized volatility in percentage, average monthly return of the BAB portfolio in percentage and average Beta spread of the $B A B$ portfolios. In addition, the table reports the correlation of the $\mathrm{BAB}$ portfolio of each market and that of the U.S. market. 
Table 2. Correlation of BAB portfolios

(3)

(4)

(5)

(1) TED Spread $-3.7471 * *$

(1.7362)

(2) VIX Index

$-0.0876$

(0.0929)

(3) $\mathrm{TA}^{B D} \times-1$

$-1.8510 * *$

(0.8552)

(4) Lev. ${ }^{B D} \times-1$

$-0.0839$

(0.0530)

(5) $\mathrm{FL}^{\text {FixedIncome }}$

$-3.0554 * * *$

(0.4525)

$\begin{array}{cccccc}\rho\left(R m^{c}, R m^{U S}\right) & 0.3589 * * * & 0.3997 * * * & 0.3154 * * * & 0.3604 * * * & 0.4024 * * * * \\ \alpha & (0.0468) & (0.0497) & (0.0441) & (0.0471) & (0.0435) \\ & \text { Yes } & \text { Yes } & \text { Yes } & \text { Yes } & \text { Yes }\end{array}$

adj. $R^{2}$

0.22

0.21

0.25

0.24

0.25

$$
\rho_{t}\left(B A B_{t}^{k}, B A B_{t}^{U S}\right)=\alpha+\delta F L_{t}+\rho_{t}\left(R m_{t}^{k}, R m_{t}^{U S}\right)+\varepsilon_{t}^{k}, \quad k \in D M
$$

The table presents time-series analysis results on the time-varying correlations of $\mathrm{BAB}$ portfolios for developed markets with that of the U.S. market with respect to five proxies of global funding illiquidity. Time-varying correlations are generated with DCC Engle (2002) methodology. P-values are calculated with double clustered standard errors (standard errors are in parenthesis) as instructed by Petersen (2009). Total asset and leverage of the broker-dealers are signed such that increase in the proxies of the funding illiquidity imply worsening of the funding condition in the economy. Estimates for the Intercept are excluded for the sake of brevity. 
Table 3. Summary Statistics of FSIs

\begin{tabular}{|c|c|c|c|c|c|c|c|}
\hline Country & EM/DM & \#Obs. & Mean & Std. & Max & Min & AutoCorr \\
\hline Argentina & EM & 190 & 0.78 & 0.42 & 2.52 & 0.20 & 0.23 \\
\hline Australia & DM & 433 & 0.64 & 0.34 & 2.06 & 0.15 & 0.27 \\
\hline Austria & DM & 433 & 0.50 & 0.23 & 1.48 & 0.15 & 0.39 \\
\hline Belgium & DM & 433 & 0.50 & 0.21 & 1.33 & 0.16 & 0.28 \\
\hline Brazil & EM & 179 & 0.52 & 0.27 & 1.73 & 0.18 & 0.48 \\
\hline Bulgaria & EM & 104 & 1.67 & 1.38 & 7.35 & 0.26 & 0.42 \\
\hline Canada & DM & 433 & 0.92 & 0.60 & 3.87 & 0.16 & 0.16 \\
\hline Chile & EM & 237 & 1.13 & 0.85 & 4.42 & 0.20 & 0.07 \\
\hline China & EM & 191 & 1.08 & 0.81 & 4.37 & 0.18 & 0.17 \\
\hline Colombia & EM & 187 & 1.28 & 1.51 & 8.42 & 0.22 & 0.94 \\
\hline Croatia & EM & 44 & 0.83 & 0.19 & 1.26 & 0.40 & 0.34 \\
\hline Cyprus & EM & 197 & 0.82 & 0.61 & 3.22 & 0.20 & 0.43 \\
\hline Czech Republic & EM & 187 & 1.59 & 1.39 & 9.59 & 0.17 & 0.17 \\
\hline Denmark & DM & 433 & 0.71 & 0.45 & 2.76 & 0.18 & 0.29 \\
\hline Egypt & EM & 152 & 1.13 & 0.99 & 6.70 & 0.19 & 0.11 \\
\hline Finland & DM & 253 & 0.49 & 0.18 & 1.23 & 0.18 & 0.31 \\
\hline France & DM & 433 & 0.54 & 0.25 & 1.39 & 0.15 & 0.28 \\
\hline Germany & $\mathrm{DM}$ & 433 & 0.52 & 0.24 & 1.51 & 0.15 & 0.31 \\
\hline Greece & EM & 231 & 1.14 & 1.06 & 5.29 & 0.22 & 0.37 \\
\hline Hong Kong & DM & 433 & 0.80 & 0.46 & 3.14 & 0.19 & 0.23 \\
\hline Hungary & EM & 201 & 0.55 & 0.21 & 1.32 & 0.22 & 0.29 \\
\hline India & EM & 231 & 1.00 & 0.72 & 4.45 & 0.23 & 0.17 \\
\hline Indonesia & EM & 228 & 0.59 & 0.27 & 1.80 & 0.24 & 0.14 \\
\hline Ireland & DM & 433 & 0.57 & 0.28 & 1.83 & 0.15 & 0.26 \\
\hline Israel & EM & 197 & 0.56 & 0.26 & 1.73 & 0.18 & 0.27 \\
\hline Italy & $\mathrm{DM}$ & 433 & 0.58 & 0.28 & 1.73 & 0.17 & 0.27 \\
\hline Japan & DM & 433 & 0.52 & 0.29 & 1.66 & 0.11 & 0.40 \\
\hline Jordan & EM & 36 & 0.48 & 0.15 & 0.83 & 0.21 & 0.18 \\
\hline Kuwait & EM & 66 & 1.00 & 0.62 & 3.53 & 0.35 & 0.11 \\
\hline Luxembourg & DM & 207 & 1.21 & 0.92 & 4.96 & 0.23 & 0.21 \\
\hline Malaysia & EM & 279 & 0.78 & 0.49 & 3.19 & 0.18 & 0.22 \\
\hline Malta & EM & 113 & 1.15 & 0.55 & 3.24 & 0.32 & -0.29 \\
\hline Mexico & EM & 239 & 0.56 & 0.27 & 1.77 & 0.20 & 0.24 \\
\hline Morocco & EM & 169 & 1.33 & 1.01 & 5.29 & 0.23 & 0.31 \\
\hline Netherlands & DM & 433 & 0.53 & 0.21 & 1.21 & 0.15 & 0.40 \\
\hline New Zealand & DM & 255 & 0.61 & 0.33 & 2.12 & 0.22 & 0.49 \\
\hline Norway & DM & 351 & 0.51 & 0.23 & 1.49 & 0.17 & 0.36 \\
\hline Oman & EM & 44 & 0.47 & 0.12 & 0.80 & 0.29 & -0.20 \\
\hline
\end{tabular}


Table 3 - continued from previous page

\begin{tabular}{lccccccc} 
Country & & & & & & & \\
& EM/DM & \#Obs. & Mean & Std. & Max & Min & AutoCorr \\
Pakistan & EM & 201 & 0.88 & 0.61 & 3.54 & 0.23 & 0.23 \\
Peru & EM & 185 & 0.64 & 0.36 & 2.09 & 0.18 & 0.29 \\
Philippines & EM & 259 & 0.76 & 0.52 & 2.99 & 0.23 & 0.32 \\
Poland & EM & 183 & 0.52 & 0.24 & 1.30 & 0.21 & 0.37 \\
Portugal & EM & 231 & 0.49 & 0.21 & 1.38 & 0.19 & 0.38 \\
Qatar & EM & 66 & 0.96 & 0.74 & 3.93 & 0.27 & 0.26 \\
Romania & EM & 150 & 1.22 & 1.03 & 4.99 & 0.23 & 0.23 \\
Russian Federation & EM & 137 & 0.67 & 0.37 & 2.14 & 0.22 & 0.05 \\
Singapore & DM & 433 & 0.63 & 0.36 & 2.26 & 0.19 & 0.26 \\
Slovenia & EM & 126 & 0.58 & 0.20 & 1.12 & 0.23 & 0.46 \\
South Africa & EM & 433 & 1.24 & 1.06 & 6.43 & 0.15 & 0.19 \\
South Korea & EM & 259 & 0.75 & 0.50 & 2.52 & 0.22 & 0.32 \\
Spain & DM & 265 & 0.47 & 0.18 & 1.15 & 0.18 & 0.27 \\
Sri Lanka & EM & 244 & 2.34 & 2.10 & 11.58 & 0.31 & 0.06 \\
Sweden & DM & 327 & 0.60 & 0.33 & 1.96 & 0.18 & 0.18 \\
Switzerland & DM & 433 & 0.62 & 0.31 & 1.80 & 0.16 & 0.24 \\
Taiwan & EM & 251 & 1.04 & 0.72 & 4.23 & 0.20 & 0.15 \\
Thailand & EM & 267 & 0.61 & 0.28 & 1.73 & 0.18 & 0.28 \\
Turkey & EM & 255 & 0.79 & 0.48 & 2.63 & 0.21 & 0.21 \\
United Kingdom & DM & 433 & 0.68 & 0.39 & 2.17 & 0.16 & 0.18 \\
United States & DM & 433 & 0.37 & 0.15 & 0.90 & 0.12 & 0.30 \\
Venezuela & EM & 230 & 1.14 & 0.89 & 5.29 & 0.24 & 0.15 \\
\hline
\end{tabular}

The table presents summary statistics for the Funding-liquidity Segmentation Indicators (FSI) constructed from BAB portfolios in each market. The sample includes 25 developed and 37 emerging markets detailed in Table 1 . The table reports the number of monthly observations for each FSI as well as their mean, standard deviation, maximum, minimum and first order autocorrelations. 
Table 4. Funding-liquidity Segmentation Indicator

\begin{tabular}{|c|c|c|c|c|c|}
\hline \multirow[t]{3}{*}{ Panel A } & \multirow{2}{*}{\multicolumn{2}{|c|}{ Average of Samples }} & \multirow{2}{*}{\multicolumn{3}{|c|}{ Pooled Panel }} \\
\hline & & & & & \\
\hline & $F \overline{S I_{D M}}$ & $F S I_{E M}$ & All Sample & $\mathrm{DM}$ & EM \\
\hline$\alpha$ & $\begin{array}{l}0.6932 * * * * \\
(0.0280)\end{array}$ & $\begin{array}{l}1.3689 * * * \\
(0.0707)\end{array}$ & $\begin{array}{l}0.82311^{* * *} \\
(0.0687)\end{array}$ & $\begin{array}{l}0.7200 * * * \\
(0.0466)\end{array}$ & $\begin{array}{l}1.9690 * * * \\
(0.1729)\end{array}$ \\
\hline$\theta$ (Time Trend) & $\begin{array}{l}-0.0003 * * * \\
(0.0001)\end{array}$ & $\begin{array}{l}-0.0012 * * * * \\
(0.0002)\end{array}$ & $\begin{array}{l}-0.0001 * * * \\
(0.0002)\end{array}$ & $\begin{array}{l}-0.0004 * * * * \\
(0.0001)\end{array}$ & $\begin{array}{l}-0.0026 * * * \\
(0.0004)\end{array}$ \\
\hline \multicolumn{6}{|l|}{ Sample Size: } \\
\hline $\mathrm{n}$ & 1 & 1 & 60 & 22 & 38 \\
\hline Time & 439 & 439 & $38-439$ & $211-439$ & $38-439$ \\
\hline Observations & 439 & 439 & 15997 & 8706 & 7291 \\
\hline
\end{tabular}

Panel B
$H_{0}: F S I_{E M}>0$
0.001
$H_{0}: F S I_{D M}>0$
0.001
$H_{0}: F S I_{E M}>F S I_{D M}$
0.001

$$
F S I_{t}^{l}=\alpha+\theta t, \quad l=[D M, E M, k=1, \ldots, K]
$$

Panel A studies the FSI and the progressively reducing barriers to investment, as proxied by the time trend, in univariate and panel regressions. In the univariate regressions, the average of FSI for developed and emerging markets are studied separately. P-values are calculated with Newey and West (1987) standard errors (standard errors are in the parenthesis). In the panel regressions, FSI for all the cross-section and subsamples of developed and emerging markets are studied in an unbalanced pooled panel, where standard errors are double clustered (Petersen (2009)). Sample size (in time-series and cross-section) of each panel regression is also reported. Panel B reports the results on the statistical significance of the FSI. It presents the results of a one-way t-test for the size of the measure of market segmentation for emerging markets relative to developed markets.P-values are calculated with Newey and West (1987) standard errors. 
Table 5. FSI and Global Funding Liquidity

\begin{tabular}{|c|c|c|c|c|c|}
\hline Panel A & (1) & (2) & (3) & (4) & (5) \\
\hline (1) TED Spread & $\begin{array}{l}0.22166^{* * *} \\
(0.0414)\end{array}$ & & & & \\
\hline (2) VIX Index & & $\begin{array}{l}0.0106 * \cdots * * \\
(0.0022)\end{array}$ & & & \\
\hline (3) $\mathrm{TA}^{B D} \times-1$ & & & $\begin{array}{c}0.1408 \\
(0.1851)\end{array}$ & & \\
\hline (4) Lev. ${ }^{B D} \times-1$ & & & & $\begin{array}{l}0.0022 * * \\
(0.0010)\end{array}$ & \\
\hline (5) $\mathrm{FL}^{\text {FixedIncome }}$ & & & & & $\begin{array}{l}0.0734 * * \\
(0.0358)\end{array}$ \\
\hline$\alpha^{k}$ & Yes & Yes & Yes & Yes & Yes \\
\hline Trend & Yes & Yes & Yes & Yes & Yes \\
\hline adj. $R^{2}$ & 0.44 & 0.46 & 0.09 & 0.09 & 0.36 \\
\hline Panel B & (1) & (2) & (3) & (4) & (5) \\
\hline (1) TED Spread & $\begin{array}{l}0.0814 * * \\
(0.0343)\end{array}$ & & & & \\
\hline (2) VIX Index & & $\begin{array}{l}0.0081 * * * \\
(0.0028)\end{array}$ & & & \\
\hline (3) $\mathrm{TA}^{B D} \times-1$ & & & $\begin{array}{l}0.0609 * * \\
(0.0242)\end{array}$ & & \\
\hline (4) Lev. $^{B D} \times-1$ & & & & $\begin{array}{l}0.0017 * * \\
(0.0008)\end{array}$ & \\
\hline (5) $\mathrm{FL}^{\text {FixedIncome }}$ & & & & & $\begin{array}{c}0.0067 \\
(0.0195)\end{array}$ \\
\hline$\alpha$ & Yes & Yes & Yes & Yes & Yes \\
\hline Control Variables: & & & & & \\
\hline Credit Spread & $\begin{array}{c}0.0164 \\
(0.0296)\end{array}$ & $\begin{array}{l}-0.0684 * \\
(0.0369)\end{array}$ & $\begin{array}{c}0.0167 \\
(0.0440)\end{array}$ & $\begin{array}{c}0.0293 \\
(0.0471)\end{array}$ & $\begin{array}{c}0.0370 \\
(0.0508)\end{array}$ \\
\hline Investment Profile & $\begin{array}{l}-0.0045 \\
(0.0073)\end{array}$ & $\begin{array}{l}-0.0028 \\
(0.0078)\end{array}$ & $\begin{array}{c}0.0077 \\
(0.0072)\end{array}$ & $\begin{array}{l}-0.0009 \\
(0.0068)\end{array}$ & $\begin{array}{l}-0.0047 \\
(0.0071)\end{array}$ \\
\hline Trade to GDP & $\begin{array}{c}0.0007 \\
(0.0005)\end{array}$ & $\begin{array}{c}0.0007 \\
(0.0005)\end{array}$ & $\begin{array}{c}0.0003 \\
(0.0006)\end{array}$ & $\begin{array}{c}0.0002 \\
(0.0006)\end{array}$ & $\begin{array}{c}0.0003 \\
(0.0005)\end{array}$ \\
\hline Market Returns & $\begin{array}{c}0.1281 \\
(0.1557)\end{array}$ & $\begin{array}{c}0.2793 * \\
(0.1590)\end{array}$ & $\begin{array}{l}-0.1241 \\
(0.0905)\end{array}$ & $\begin{array}{l}-0.1292 \\
(0.0978)\end{array}$ & $\begin{array}{c}-0.0552 \\
(0.1071)\end{array}$ \\
\hline
\end{tabular}


Table 5 - continued from previous page

(2)

(3)

(4)

(5)

Market Cap. to GDP

$\begin{array}{ccccc} & & -0.0001 & -0.0001 & -0.0001 \\ 0.2248 * & (0.0002) & (0.0002) & (0.0002) \\ (0.1357) & 0.3630 * * * & 0.2322 * * & 0.1953 * & 0.1658 \\ & (0.1346) & (0.0956) & (0.1044) & (0.1186)\end{array}$

Panel C

(1)

(2)

(3)

(4)

(5)
(1) TED Spread
$0.1519 * * *$
(0.0472)

(2) VIX Index

$0.0667 *$

(3) $\mathrm{TA}^{B D} \times-1$

(0.0303)

(4) Lev. $^{B D} \times-1$

0.0019

(0.0359)

(5) $\mathrm{FL}^{\text {FixedIncome }}$

(0.0366)

\begin{tabular}{|c|c|c|c|c|}
\hline & & & & $\begin{array}{c}0.0823 \\
(0.0485)\end{array}$ \\
\hline Yes & Yes & Yes & Yes & Yes \\
\hline Yes & Yes & Yes & Yes & Yes \\
\hline
\end{tabular}

$\alpha^{k}$

Trend

(1)

(2)

(3)

(4)

(5)
(1) TED Spread
$-0.1001 * *$
(0.0435)

(2) VIX Index

$-0.0107$

(3) $\mathrm{TA}^{B D} \times-1$

(0.0136)

(4) Lev. ${ }^{B D} \times-1$

$-0.0437 *$

(0.0253)

(5) $\mathrm{FL}^{\text {FixedIncome }}$

$-0.0150$

(0.1499)

\begin{tabular}{lllllc} 
& & & & $(0.0522)$ \\
$\alpha^{k}$ & Yes & Yes & Yes & Yes & Yes \\
Trend & Yes & Yes & Yes & Yes & Yes \\
\hline
\end{tabular}

Panel A: $F S I_{t}^{k}=\alpha^{k}+\delta F L_{t}+\theta t+\varepsilon_{t}^{k}$,

$k \in D M$

Panel B: $F S I_{t}^{k}=\alpha+\delta F L_{t}+\gamma$ Cont.Var. $+\varepsilon_{t}^{k}$,

$k \in D M$

Panel C: $F S I_{t}^{k}=\alpha^{k}+\delta I\left[F L_{t} \in 0.75^{t h}\right]+\theta t+\varepsilon_{t}^{k}$

$k \in D M$

Panel D: $F S I_{t}^{k}=\alpha^{k}+\delta I\left[F L_{t} \in 0.25^{t h}\right]+\theta t+\varepsilon_{t}^{k}, \quad k \in D M$ 
Panel A reports the regression results of the FSI of the developed markets with respect to five global funding illiquidity measures. These regressions include country intercepts and time trend to capture the effect of country-specific differences between markets and the reduction of barriers to investment during time. Panel B reports the results of the similar regression which includes control variables and excludes country fixed effects and the time trend. Panels $C$ and D respectively report the results of the forth and first quantile regression, implemented with a dummy variable. P-values are double clustered (standard errors are reported in parenthesis). Total asset and leverage of the broker-dealers are signed such that increase in the proxies of the funding illiquidity imply worsening of the funding condition in the economy. The estimates for the intercepts and the trend are not reported for the sake of brevity. 
Table 6. SEG and Global Funding Illiquidity

\section{Panel A}

(1)

(2)

(3)

(4)

(5)

(1) TED Spread $0.5474 * * *$

(0.1294)

(2) VIX Index

$0.0617 * * * *$
$(0.0062)$

(3) $\mathrm{TA}^{B D} \times-1$

$2.7422 * * *$

(0.5702)

(4) Lev. $^{B D} \times-1$

$-0.0006$

(5) $\mathrm{FL}^{\text {FixedIncome }}$ (0.0062)

$\alpha^{k}$

Trend

Yes

Yes

adj. $\mathrm{R}^{2}$

0.17

Yes

Yes

Yes

0.18

0.20

$0.1704 * * *$

(0.0489)

Yes

Yes

0.18

\section{Panel B}

(1)

(2)

(3)

(4)

(5)

$\begin{array}{ll}\text { (1) TED Spread } & 0.4746 * * \\ (0.2329)\end{array}$

(2) VIX Index

0.0024

(0.0105)

(3) $\mathrm{TA}^{B D} \times-1$

0.4238 *

(4) Lev. ${ }^{B D} \times-1$

(0.2516)

(5) $\mathrm{FL}^{\text {FixedIncome }}$

(0.0087)

(5) Fir Firdincome

$\alpha$

Yes

Yes

Yes

Yes

0.0923

(0.0881)

Yes

Control Variables:

Credit Spread

$2.4653 * * *$
$(0.4206)$

Investment Pro-

$-0.1969 * * *$

$2.1547 * * *$

$1.7994 * * *$

(0.3332)

(0.6419)

$-0.2207 \div$

-0.1726 *

$1.6989 * * *$

$2.6536 * * *$

file

(0.0583)

(0.0457)

(0.0897)

(0.0728) 
Table 6 - continued from previous page

(1)

\begin{tabular}{llllll}
\hline Capital Account & -0.0281 & -0.0166 & $-0.0345 *$ & $-0.0345 *$ & -0.0304 \\
Openness & & & & \\
& $(0.0189)$ & $(0.0208)$ & $(0.0191)$ & $(0.0184)$ & $(0.0190)$ \\
Trade to GDP & 0.0002 & $0.0058 *$ & $0.0110 * * *$ & $0.0111 * * *$ & 0.0001 \\
& $(0.0023)$ & $(0.0031)$ & $(0.0035)$ & $(0.0035)$ & $(0.0023)$ \\
Market Cap. to & & & $-0.0012 * *$ & $-0.0012 * *$ & \\
GDP & & & & \\
Market Liquid- & 1.7911 & 0.8234 & $0.0005)$ & $(0.0005)$ & \\
ity & & & & 0.4171 & 1.7897 \\
Market Returns & $-2.6033 * * *$ & $(1.3058)$ & $(1.2075)$ & $(1.2320)$ & $(1.1209)$ \\
& $(0.4772)$ & $(0.4028)$ & $-1.8357 * * *$ & $-2.0112 * * *$ & $-2.7660 * * *$ \\
adj. $R^{2}$ & 0.24 & 0.21 & $0.3276)$ & $(0.3274)$ & $(0.4316)$ \\
\hline
\end{tabular}

$$
\begin{array}{lrl}
\text { Panel A: } S E G_{t}^{k}=\alpha^{k}+\delta F L_{t}+\theta t+\varepsilon_{t}^{k}, & k \in D M, \\
\text { Panel B: } S E G_{t}^{k}=\alpha+\delta F L_{t}+\gamma \text { Cont.Var. }+\varepsilon_{t}^{k}, & k \in D M,
\end{array}
$$

The table presents test results on the SEG index, the measure of market segmentation introduced in Bekaert et al. (2011), for developed markets conditional on five proxies of global funding illiquidity. Panel A reports the estimation for the full sample period from 1973 to 2014. These regressions include country intercepts and time trend to capture the effect of country-specific differences between markets and the reduction of barriers to investment during time. Panel B, includes a set of explanatory factors that Bekaert et al. (2011) show explain market segmentation. P-values are calculated with double clustered standard errors (standard errors are in parenthesis). Total asset and leverage of the broker-dealers are signed such that increase in the proxies of the funding illiquidity imply worsening of the funding condition in the economy. Estimates for the country intercepts, time trend and control variables are excluded for the sake of brevity. 
Table 7. SEG and Global Funding Illiquidity: Quantile Regression

\begin{tabular}{|c|c|c|c|c|c|}
\hline Panel A & (1) & (2) & (3) & (4) & (5) \\
\hline (1) TED Spread & $\begin{array}{l}0.0073^{* * *} \\
(0.0027)\end{array}$ & & & & \\
\hline (2) VIX Index & & $\begin{array}{l}0.0062^{* * *} \\
(0.0021)\end{array}$ & & & \\
\hline (3) $\mathrm{TA}^{B D} \times-1$ & & & $\begin{array}{c}0.0015 \\
(0.0022)\end{array}$ & & \\
\hline (4) Lev. $^{B D} \times-1$ & & & & $\begin{array}{l}0.0042^{* *} \\
(0.0018)\end{array}$ & \\
\hline (5) $\mathrm{FL}^{\text {FixedIncome }}$ & & & & & $\begin{array}{c}0.0029 \\
(0.0022)\end{array}$ \\
\hline Investment Profile $\times-1$ & $\begin{array}{c}0.0018 \\
(0.0016)\end{array}$ & $\begin{array}{c}0.0017 \\
(0.0014)\end{array}$ & $\begin{array}{c}0.0012 \\
(0.0025)\end{array}$ & $\begin{array}{c}0.0012 \\
(0.0025)\end{array}$ & $\begin{array}{c}0.0012 \\
(0.0019)\end{array}$ \\
\hline Trade to GDP $\times-1$ & $\begin{array}{l}0.0117^{* * *} \\
(0.0031)\end{array}$ & $\begin{array}{l}0.0135^{* * *} \\
(0.0042)\end{array}$ & $\begin{array}{l}0.0135^{* * *} \\
(0.0026)\end{array}$ & $\begin{array}{l}0.0129^{* * *} \\
(0.0025)\end{array}$ & $\begin{array}{l}0.0140^{* * *} \\
(0.0027)\end{array}$ \\
\hline Market Returns $\times-1$ & $\begin{array}{l}0.0053^{* * *} \\
(0.0013)\end{array}$ & $\begin{array}{l}0.0049^{* * *} \\
(0.0015)\end{array}$ & $\begin{array}{l}0.0064^{* * *} \\
(0.0018)\end{array}$ & $\begin{array}{l}0.0067^{* * *} \\
(0.0017)\end{array}$ & $\begin{array}{l}0.0059^{* * *} \\
(0.0016)\end{array}$ \\
\hline Market Liquidity & $\begin{array}{c}0.0016 \\
(0.0017)\end{array}$ & $\begin{array}{c}0.0019 \\
(0.0016)\end{array}$ & $\begin{array}{c}-0.0011 \\
(0.0023)\end{array}$ & $\begin{array}{c}-0.0008 \\
(0.0021)\end{array}$ & $\begin{array}{c}0.0011 \\
(0.0019)\end{array}$ \\
\hline$\alpha$ & $\begin{array}{l}0.0182^{* * *} \\
(0.0010)\end{array}$ & $\begin{array}{l}0.0172^{* * *} \\
(0.0010)\end{array}$ & $\begin{array}{l}0.0215^{* * *} \\
(0.0021)\end{array}$ & $\begin{array}{l}0.0222^{* * *} \\
(0.0018)\end{array}$ & $\begin{array}{l}0.0190^{* * *} \\
(0.0013)\end{array}$ \\
\hline $\operatorname{adj} . R^{2}$ & 0.19 & 0.17 & 0.12 & 0.13 & 0.16 \\
\hline Panel B & (1) & (2) & (3) & (4) & (5) \\
\hline (1) TED Spread & $\begin{array}{r}-0.0008 \\
(0.0014)\end{array}$ & & & & \\
\hline (2) VIX Index & & $\begin{array}{r}-0.0025 \\
(0.0016)\end{array}$ & & & \\
\hline (3) $\mathrm{TA}^{B D} \times-1$ & & & $\begin{array}{l}-0.0160^{* * *} \\
(0.0025)\end{array}$ & & \\
\hline (4) Lev. $^{B D} \times-1$ & & & & $\begin{array}{l}-0.0161^{* * *} \\
(0.0019)\end{array}$ & \\
\hline (5) $\mathrm{FL}^{\text {FixedIncome }}$ & & & & & $\begin{array}{c}0.0010 \\
(0.0019)\end{array}$ \\
\hline Investment Profile $\times-1$ & $\begin{array}{l}-0.0054^{* * *} \\
(0.0016)\end{array}$ & $\begin{array}{c}-0.0035^{* *} \\
(0.0016)\end{array}$ & $\begin{array}{r}-0.0025^{*} \\
(0.0015)\end{array}$ & $\begin{array}{r}-0.0024^{*} \\
(0.0014)\end{array}$ & $\begin{array}{l}-0.0060^{* * *} \\
(0.0019)\end{array}$ \\
\hline
\end{tabular}


Table 7 - continued from previous page

\begin{tabular}{lccccc}
\hline & $(1)$ & $(2)$ & $(3)$ & $(4)$ & $(5)$ \\
\hline \multirow{2}{*}{ Trade to GDP $\times-1$} & $-0.0049^{* * *}$ & -0.0025 & -0.0007 & -0.0007 & $-0.0048^{* *}$ \\
& $(0.0018)$ & $(0.0018)$ & $(0.0017)$ & $(0.0016)$ & $(0.0019)$ \\
Market Returns $\times-1$ & $-0.0024^{* *}$ & $-0.0024^{* *}$ & $-0.0039^{* * *}$ & $-0.0040^{* * *}$ & $-0.0021^{*}$ \\
& $(0.0011)$ & $(0.0011)$ & $(0.0011)$ & $(0.0011)$ & $(0.0011)$ \\
Market Liquidity & 0.0007 & -0.0027 & 0.0001 & 0.0001 & 0.0013 \\
& $(0.0025)$ & $(0.0017)$ & $(0.0020)$ & $(0.0021)$ & $(0.0026)$ \\
$\alpha$ & $0.0290^{* * *}$ & $0.0270^{* * *}$ & $0.0243^{* * *}$ & $0.0242^{* * *}$ & $0.0287^{* * *}$ \\
& $(0.0026)$ & $(0.0027)$ & $(0.0025)$ & $(0.0024)$ & $(0.0025)$ \\
adj. $\mathrm{R}^{2}$ & 0.05 & 0.04 & 0.16 & 0.16 & 0.05 \\
\hline
\end{tabular}

Panel A: $S E G_{t}^{k}=\alpha+\delta I\left[F L_{t} \in 0.75^{t h}\right]+\gamma I\left[\right.$ Cont.Var. $\left.\in 0.75^{t h}\right]+\varepsilon_{t}^{k}, \quad k \in D M$,

Panel B: $S E G_{t}^{k}=\alpha+\delta I\left[F L_{t} \in 0.25^{t h}\right]+\gamma I\left[\right.$ Cont.Var. $\left.\in 0.25^{t h}\right]+\varepsilon_{t}^{k}, \quad k \in D M$,

The table presents quantile regression results on the SEG index for developed markets conditional on proxies of five global funding illiquidity measures and a set of explanatory factors that Bekaert et al. (2011) show explain market segmentation. Panel A and B report the forth and first quantile regression, implemented with dummy variables, respectively. Investment Profile, Trade to GDP, and Market Returns are signed such that their forth quantile coincide with the periods of increases in SEG index. Total asset and leverage of the broker-dealers are signed such that increase in the proxies of the funding liquidity imply worsening of the funding condition in the economy. P-values are calculated with double clustered standard errors (standard errors are in parenthesis). Estimates for the country intercepts, time trend and control variables are excluded for the sake of brevity. 
Table 8. Cross-section of Segmentation and Local Funding Liquidity

Panel A

(1)

$\overline{\hat{\Psi}^{k}}$

$\alpha$

Control Variables:

Investment Profile

Capital Account

Openness

Trade to GDP

Liquidity

Market Cap. to GDP

$0.4247 * * *$

(0.1110)

Yes

(3)

(4)

(5)

$\begin{array}{cccc}0.1561 * * & 0.3796 * * * & 0.4395 * * & 0.1981 \\ 0.0634) & (0.0968) & (0.1760) & (0.0745) \\ \text { Yes } & \text { Yes } & \text { Yes } & \text { Yes }\end{array}$

0.0119

(0.0147)
0.0007

(0.0004)

0.0005

$0.0007 * * * *$

(0.0004)

(0.0003)

$0.8347 * *$

0.3937

(0.3236)

(0.5747)

$-0.0005$

(0.0005)

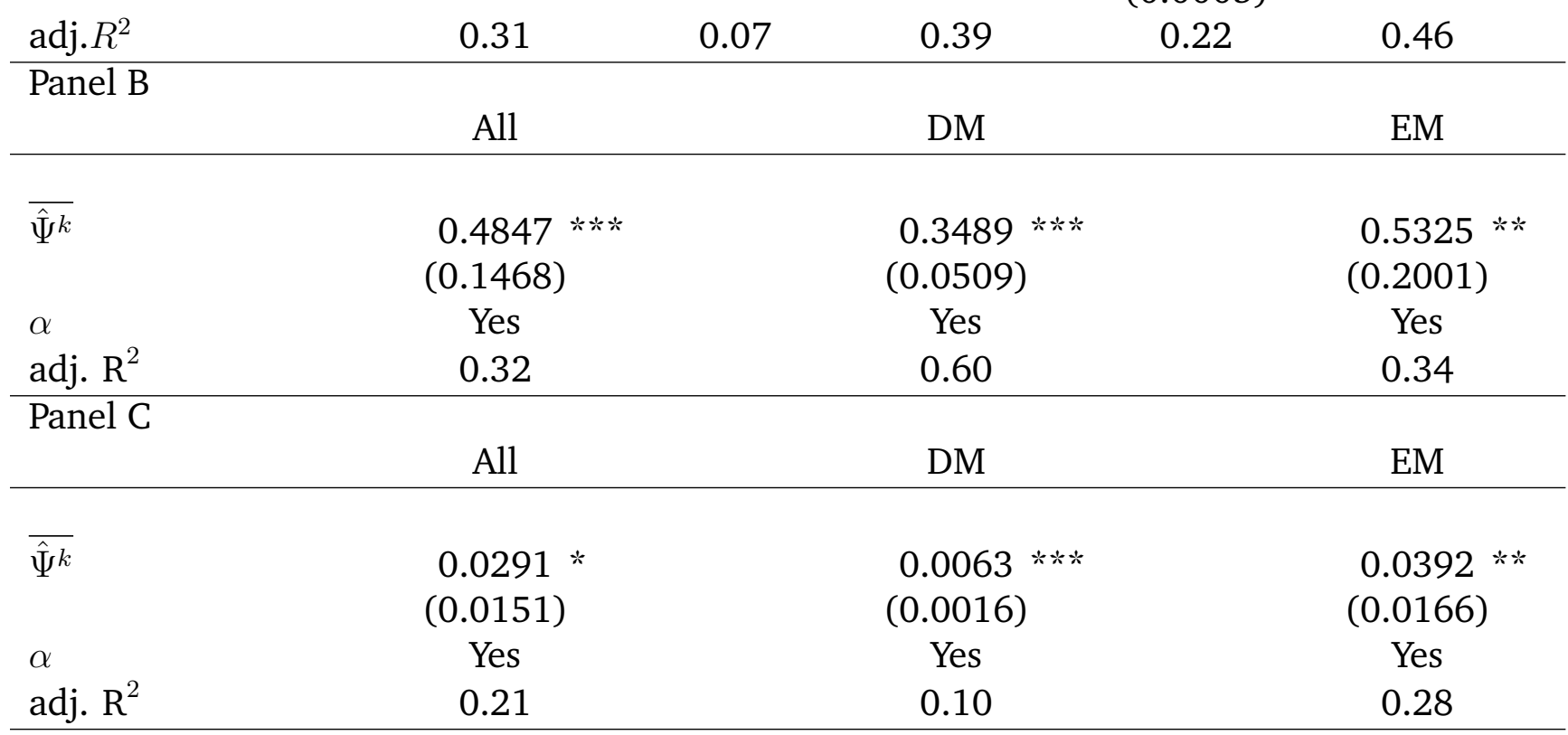

Panel A: $\overline{F S I^{k}}=\alpha+\delta \overline{\hat{\Psi}^{k}}+\gamma \overline{\text { Cont.Var. }^{k}}+\varepsilon^{k}$,

Panel B: $\overline{F S I^{k}}=\alpha+\delta \overline{\hat{\Psi}^{k}}+\varepsilon^{k}$,

Panel C: $\overline{S E G^{k}}=\alpha+\delta \overline{\Psi^{k}}+\varepsilon^{k}$,

The table presents cross-sectional test results on segmentation with respect to local funding illiquidity. Panel A presents the results for the FSI, as an indicator of the market segmentation, on the average of the estimated local funding illiquidity $\Psi_{t}^{k}$, and a series of control variables. Panel B presents the estimates of a similar cross-sectional regressions in three subsamples. Panel C re-estimates the same test studying the BHLS measure of market segmentation, $S E G$ index, introduced in Bekaert et al. (2011) . 
Table 9. Time-series of Segmentation and Local Funding Liquidity

Panel A

(3)

(4)

(5)

\begin{tabular}{|c|c|c|c|c|c|}
\hline$\hat{\Psi}_{t}^{k}$ & $\begin{array}{l}0.3046 * * * * \\
(0.0349)\end{array}$ & $\begin{array}{l}0.1878 * * * \\
(0.0484) \\
\text { Yes }\end{array}$ & $\begin{array}{l}0.3048 * * * \\
(0.0350)\end{array}$ & $\begin{array}{l}0.3611 * * * \\
(0.0945) \\
\text { Yes }\end{array}$ & $\begin{array}{l}0.1721 * * * \\
(0.0444)\end{array}$ \\
\hline $\begin{array}{l}\alpha \\
\text { Control Variables: }\end{array}$ & Yes & Yes & Yes & Yes & Yes \\
\hline Investment Profile & & & & & $\begin{array}{l}-0.0095 \\
(0.0099)\end{array}$ \\
\hline $\begin{array}{l}\text { Capital Account } \\
\text { Openness }\end{array}$ & & $\begin{array}{l}0.0006 \\
(0.0008)\end{array}$ & & & \\
\hline Trade to GDP & & $\begin{array}{l}-0.0003 \\
(0.0008)\end{array}$ & & & $\begin{array}{l}-0.0018 * * * \\
(0.0005)\end{array}$ \\
\hline Liquidity & & & $\begin{array}{c}0.2158 \\
(0.2447)\end{array}$ & & $\begin{array}{l}-0.2582 * \\
(0.1448)\end{array}$ \\
\hline Market Cap. to GDP & & & & $\begin{array}{l}-0.0001 \\
(0.0001)\end{array}$ & \\
\hline $\operatorname{adj} . R^{2}$ & 0.29 & 0.18 & 0.29 & 0.28 & 0.22 \\
\hline Panel B & All & & DM & & EM \\
\hline$\hat{\Psi}_{t}^{k}$ & $\begin{array}{l}0.4086 * * * \\
(0.0850)\end{array}$ & & $\begin{array}{l}0.3294 * * * \\
(0.0582)\end{array}$ & & $\begin{array}{l}0.4385 * * * \\
(0.1238)\end{array}$ \\
\hline $\begin{array}{l}\alpha^{k} \\
\text { adj. } R^{2}\end{array}$ & $\begin{array}{l}\text { Yes } \\
0.22\end{array}$ & & $\begin{array}{l}\text { Yes } \\
0.34\end{array}$ & & $\begin{array}{c}\text { Yes } \\
0.21\end{array}$ \\
\hline Panel C & All & & DM & & EM \\
\hline $\begin{array}{l}\hat{\Psi}_{t}^{k} \\
\alpha^{k} \\
\text { adj. } \mathrm{R}^{2}\end{array}$ & $\begin{array}{l}0.1009 * * * \\
(0.0431) \\
\text { Yes } \\
0.09\end{array}$ & & $\begin{array}{c}0.1665 * * \\
(0.0837) \\
\text { Yes } \\
0.24\end{array}$ & & $\begin{array}{c}0.1110 * * \\
(0.0514) \\
\text { Yes } \\
0.09\end{array}$ \\
\hline
\end{tabular}

Panel A: $F S I_{t}^{k}=\alpha^{k}+\delta \hat{\Psi}_{t}^{k}+\gamma$ Cont.Var ${ }_{t}^{k}+\varepsilon_{t}^{k}$,

Panel B: $F S I_{t}^{k}=\alpha^{k}+\delta \hat{\Psi}_{t}^{k}+\varepsilon_{t}^{k}$,

Panel C: $S E G^{k}=\alpha^{k}+\delta \hat{\Psi}_{t}^{k}+\varepsilon_{t}^{k}$,

The table presents time-series test results on segmentation with respect to the local funding liquidity. Panel A presents the results for the FSI, as an indicator of market segmentation, on the estimated local funding illiquidity $\Psi_{t}^{k}$, and a series of control variables. Panel B presents the estimates of a similar test in three subsamples. Panel $\mathrm{C}$ re-estimates the same test studying the BHLS measure of market segmentation, $S E G$ index, introduced in Bekaert et al. (2011). 
Table 10. U.S. FSI and Funding Liquidity

\begin{tabular}{|c|c|c|c|c|c|}
\hline Panel A & (1) & (2) & (3) & (4) & (5) \\
\hline (1) TED Spread & $\begin{array}{l}0.7455 * * \\
(0.3693)\end{array}$ & & & & \\
\hline (2) VIX Index & & $\begin{array}{c}0.0068 \\
(0.0073)\end{array}$ & & & \\
\hline (3) $\mathrm{TA}^{B D} \times-1$ & & & $\begin{array}{l}0.1211 * \\
(0.0631)\end{array}$ & & \\
\hline (4) Lev. $^{B D} \times-1$ & & & & $\begin{array}{c}0.0120 * \\
(0.0063)\end{array}$ & \\
\hline (5) $\mathrm{FL}^{\text {FixedIncome }}$ & & & & $x^{2}$ & $\begin{array}{c}0.2564 \\
(0.2147)\end{array}$ \\
\hline$\alpha$ & Yes & Yes & Yes & Yes & Yes \\
\hline Panel B & (1) & (2) & (3) & (4) & (5) \\
\hline (1) TED Spread & $\begin{array}{l}9.9135 * * \\
(4.0248)\end{array}$ & & & & \\
\hline (2) VIX Index & & $\begin{array}{l}0.4145 * \\
(0.2520)\end{array}$ & & & \\
\hline (3) $\mathrm{TA}^{B D} \times-1$ & & & $\begin{array}{c}0.5188 \\
(1.2615)\end{array}$ & & \\
\hline (4) Lev. $^{B D} \times-1$ & & & & $\begin{array}{c}0.0556 \\
(0.0871)\end{array}$ & \\
\hline (5) $\mathrm{FL}^{\text {FixedIncome }}$ & & & & & $\begin{array}{c}0.8361 \\
(1.4905)\end{array}$ \\
\hline$\alpha$ & Yes & Yes & Yes & Yes & Yes \\
\hline
\end{tabular}

Panel A: $S E G_{t}^{U S}=\alpha+\delta F L_{t}+\varepsilon_{t}^{U S}$,

Panel B: $F S I_{t}^{U S}=\alpha+\delta F L_{t}+\varepsilon_{t}^{U S}$,

Panel A and B reports the regression results of the BHLS measure of market segmentation and FSI of the U.S. market with respect to funding illiquidity measures in the U.S. market. P-values are calculated with Newey and West (1987) standard errors (standard errors are reported in parenthesis). Total asset and leverage of the broker-dealers are signed such that increase in the proxies of the funding liquidity imply worsening of the funding condition in the economy. The estimates for the intercepts are not reported for the sake of brevity. 


\section{B Figures}

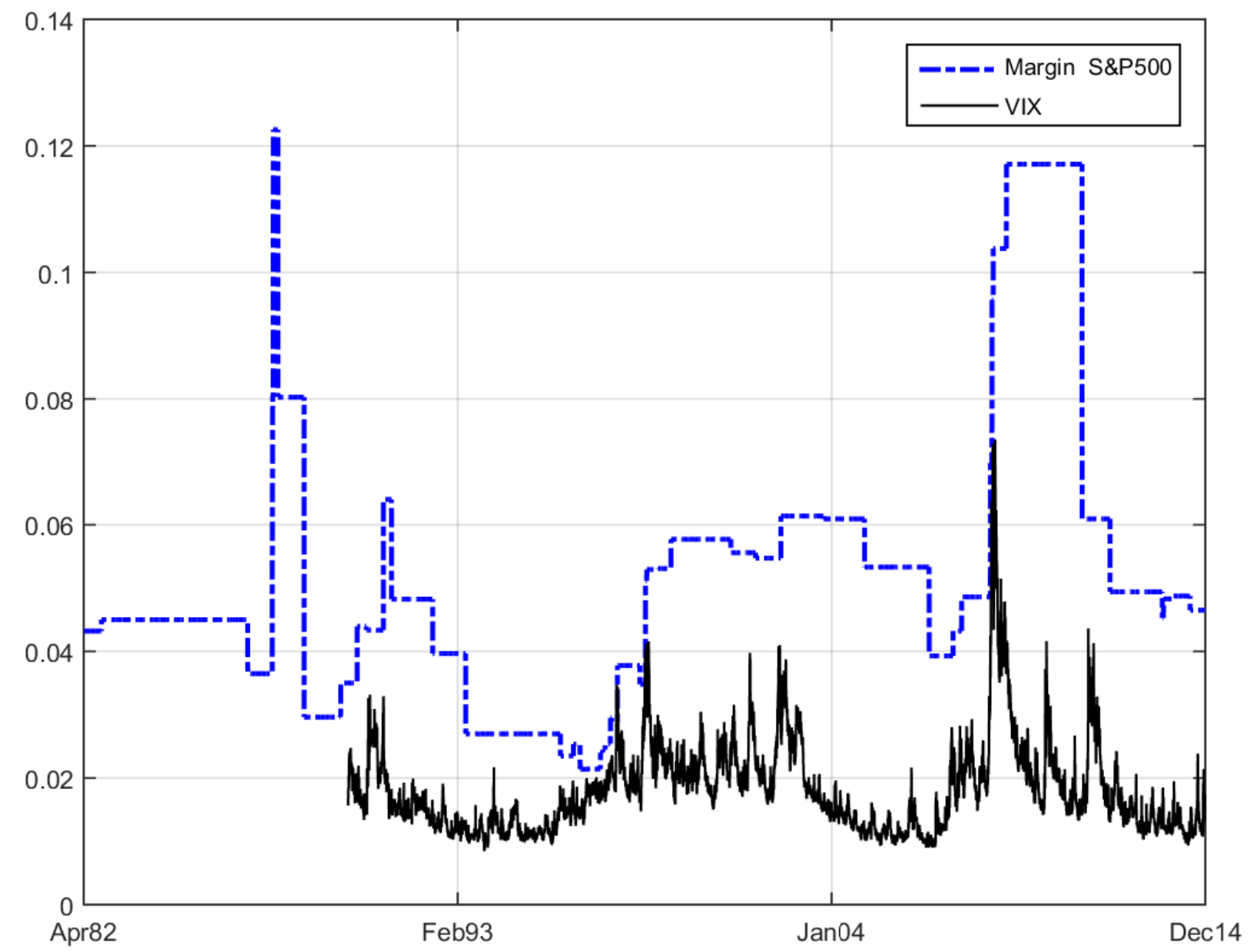

Figure 1. Margins for S\&P 500 futures: The figure plots minimum performance bond requirement for S\&P 500 stock index futures contracts for members of Chicago Mercantile Exchange with dash-dot line in blue. Here, the dollar value of the initial margin requirements are divided by the dollar value of a futures contract (value of the S\&P 500 index times the contract size). The VIX index (implied volatility) is superimposed on the graph with dark solid line. Source: CME group website 


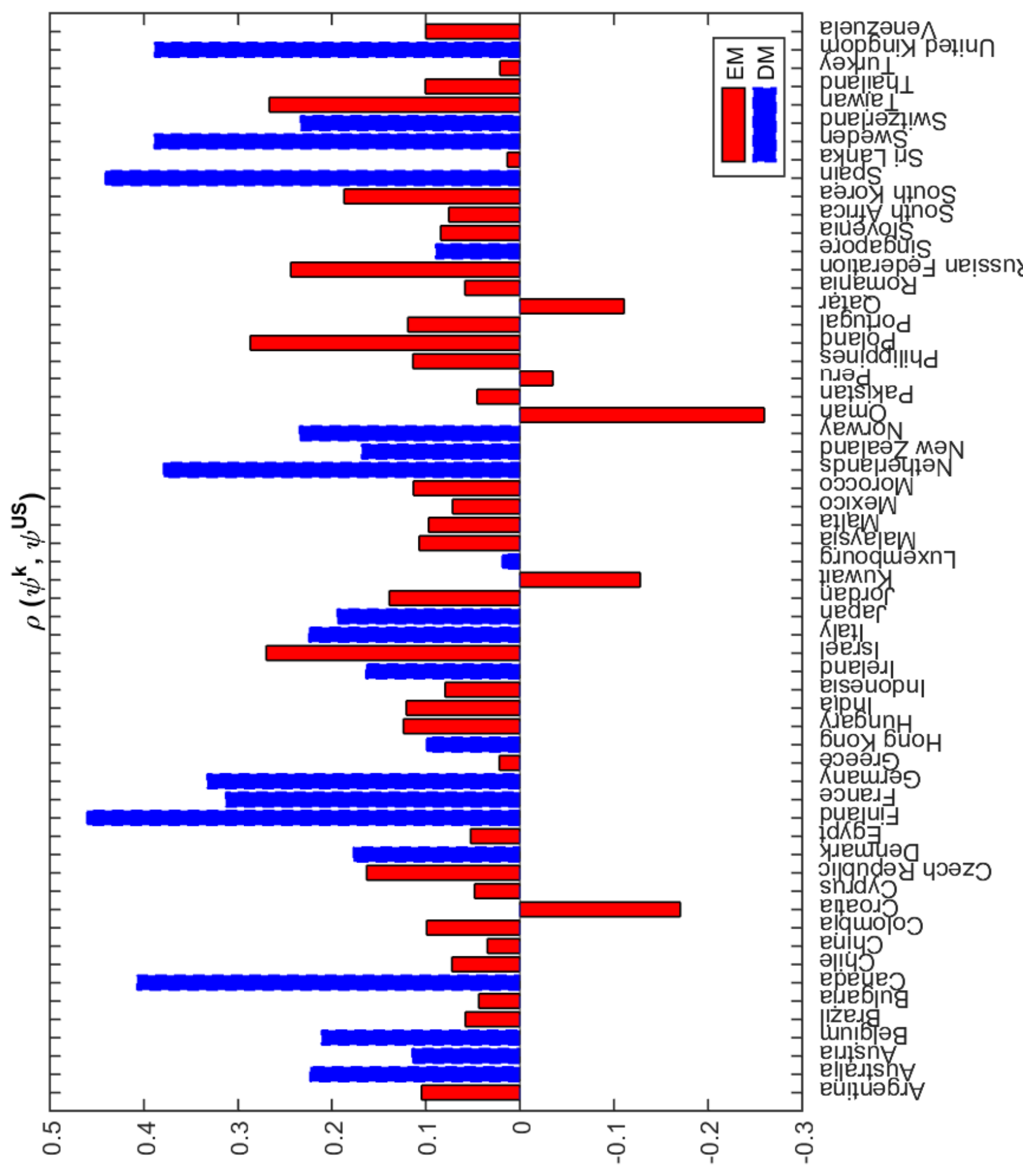

$\stackrel{\infty}{\Xi} \dot{0}$

븐

当

\& $\overbrace{2}^{2}$

Чै

눙

苋号

3 选弯

完范

푸

ชู चี

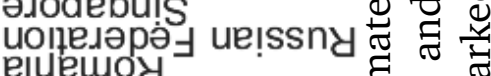

eluemoy . ज :

Jejeo

énnuod

souldd!! पa

กرว

के 00

ช สี ส

I

牢造

건

NemuO

puejeว7 MәN

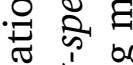

䨔

突志

- \& द

든 चु

ए

空

입 তृ

등 둥

\& 0

Eஸे⿺ 丶万

ฆ口

올

$\because 4$

등

60 工

드를

焉

는

○

코원

돈

언 준

。ั

ง...

ง तี

$\exists \frac{1}{0}$

. 


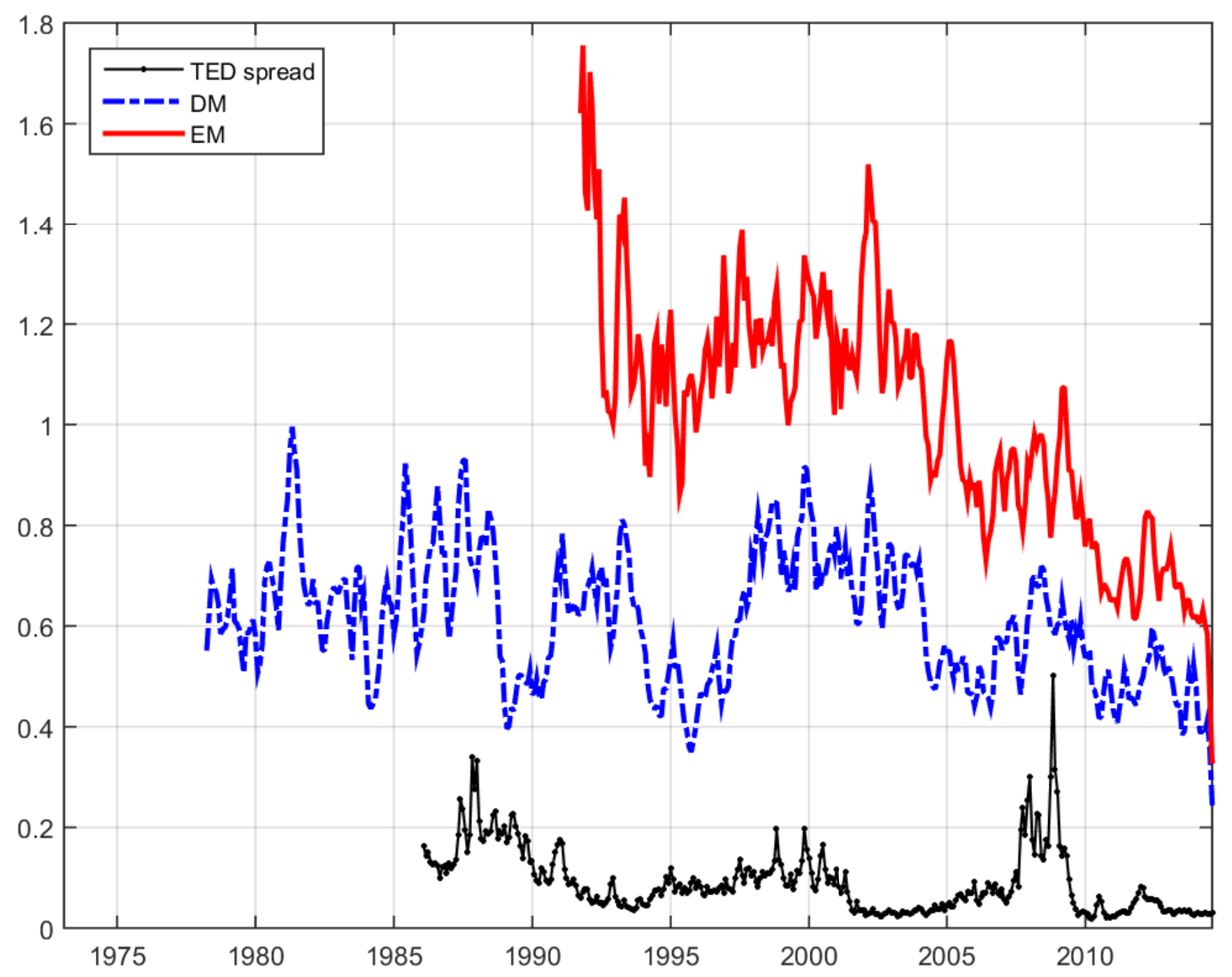

Figure 3. Funding-implied Segmentation Indicator: The plot shows the average of FSI for developed markets (in blue dash-dot line) and emerging markets (in solid red line). The measure is constructed based on the value-weighted discrepancies of the estimated shadow price of the funding constraint for the global representative investor, extracted from each market BAB portfolios. The TED spread is shown in black with asterisk marker. 